\title{
An examination of adolescent nicotine withdrawal symptoms: A validation of the Nicotine Withdrawal Assessment for Youth
}

\author{
Matthew E. Goldfine \\ West Virginia University
}

Follow this and additional works at: https://researchrepository.wvu.edu/etd

\section{Recommended Citation}

Goldfine, Matthew E., "An examination of adolescent nicotine withdrawal symptoms: A validation of the Nicotine Withdrawal Assessment for Youth" (2009). Graduate Theses, Dissertations, and Problem Reports. 2924.

https://researchrepository.wvu.edu/etd/2924

This Dissertation is protected by copyright and/or related rights. It has been brought to you by the The Research Repository @ WVU with permission from the rights-holder(s). You are free to use this Dissertation in any way that is permitted by the copyright and related rights legislation that applies to your use. For other uses you must obtain permission from the rights-holder(s) directly, unless additional rights are indicated by a Creative Commons license in the record and/ or on the work itself. This Dissertation has been accepted for inclusion in WVU Graduate Theses, Dissertations, and Problem Reports collection by an authorized administrator of The Research Repository @ WVU.

For more information, please contact researchrepository@mail.wvu.edu. 
An Examination of Adolescent Nicotine Withdrawal Symptoms: A Validation of the Nicotine Withdrawal Assessment for Youth

\title{
Matthew E. Goldfine
}

\author{
Dissertation submitted to the \\ Eberly College of Arts and Sciences \\ at West Virginia University \\ in partial fulfillment of the requirements \\ for the degree of
}
Doctor of Philosophy
in
Clinical Psychology

\author{
Steven A. Branstetter, Ph.D., Chair \\ Cheryl B. McNeil, Ph.D. \\ Kimberly A. Horn, Ed.D. \\ Katherine H. Karraker, Ph.D. \\ Kevin T. Larkin, Ph.D. \\ Department of Psychology
}

\section{Morgantown, West Virginia \\ 2009}

Keywords: Nicotine Withdrawal, Adolescent, Nicotine Withdrawal Assessment for Youth, NWAY

Copyright 2009 Matthew E. Goldfine 


\begin{abstract}
An Examination of Adolescent Nicotine Withdrawal Symptoms:

A Validation of the Nicotine Withdrawal Assessment for Youth
\end{abstract}

\title{
Matthew E. Goldfine
}

The present study evaluated the nicotine withdrawal symptoms of current adolescent cigarette smokers and examined the psychometric properties of the Nicotine Withdrawal Assessment for Youth (N-WAY), a new measure of adolescent nicotine withdrawal symptoms. Smokers and nonsmokers, ranging in age from 13-19 years old, were found to report significantly different rates of 10 of 19 purported nicotine withdrawal symptoms: anger, headaches, alertness, feeling depressed, nervousness, dizziness, irritability, conflict with family, conflict with school staff, and cigarette cravings. In addition, smokers were found to be significantly older and consume more daily caffeine than nonsmokers. The data imply that caffeine use may ameliorate certain nicotine withdrawal symptoms or caffeine withdrawal may be more responsible for symptoms falsely attributed to nicotine withdrawal. There were no indications of different rates of restlessness, trouble concentrating, feeling tired, feeling stressed, feeling hyper, waking up during sleep, hunger, trouble falling asleep, or conflict with friends among smokers and nonsmokers. Results also suggested that light smokers may experience higher rates of day-to-day nicotine withdrawal symptoms than heavy smokers. Despite being more dependent on nicotine, heavy smokers, through their frequent administration of nicotine, may be better able to prevent or quickly alleviate withdrawal symptoms than light smokers. An examination of the N-WAY demonstrated acceptable test-retest reliability (total symptom score $[r=.78]$ and impact score $[r=.74]$ ) and internal consistency (symptom items Cronbach's $\alpha=.84$ and impact items Cronbach's $\alpha=.92$ ). Its total symptom and impact score both accurately discriminated current smokers from nonsmokers. There was weak concurrent validity with an established measure of nicotine dependence, the Modified Fagerström Tolerance Questionnaire. This was hypothesized to support that the N-WAY validly measured nicotine withdrawal symptoms, a distinct construct from nicotine dependence symptoms. Other correlates of nicotine withdrawal symptoms, such as number of daily cigarettes smoked and prior quit attempts, accurately predicted total N-WAY impact score, further indicating that the N-WAY is a valid assessment of adolescent nicotine withdrawal symptoms. These results suggest that although adolescent smokers experience a number of nicotine withdrawal symptoms, there are a number of symptoms that nonsmokers report at equal rates and may be best explained as a normative adolescent experience. 


\section{Acknowledgements}

There are many individuals who deserve thanks for their support and guidance during this project and my time as a graduate student.

To my mentor and dissertation chair, Dr. Steve Branstetter: Your methodological brilliance has made me a stronger researcher. Your kindness has made me a better person. Thank you for always believing in me.

To my mentor and role-model, Dr. Cheryl McNeil: As if your professional achievements weren't enough, you are also one of the most considerate, kind, and compassionate people I have ever met. Your presence has been a gift and I would not have reached this point without you.

To Dr. Kimberly Horn: Your enthusiasm for my dissertation and support throughout the research process was integral in keeping me motivated. Thank you for bringing me along for the adolescent smoking cessation ride. I feel privileged to have worked with you. The N-WAY was developed by Dr. Horn as part of her fellowship with the University of Pittsburgh's Center for Education and Drug Abuse Research. Special acknowledgement is extended to Dr. Ralph Tarter (University of Pittsburgh) and Dr. Geri Dino (West Virginia University) for their contributions to the N-WAY development and evaluation.

To the other members of my dissertation committee: Thank you to Dr. Katherine Karraker, whose attention to detail has pushed me to become a better researcher and writer. You are the embodiment of professionalism. Thank you to Dr. Kevin Larkin, who continues to find new and exciting ways to train students. Your love of psychology is contagious.

To the research assistants of the Adolescent Research Laboratory: You went above and beyond expectations to help a graduate student in need. Additionally, Cheryl Conaway of North Marion High School was integral in recruiting teen smokers. My dissertation could not have happened without you. Thank you tremendously for your assistance.

To my WVU friends and colleagues: Brian Ayotte, Clare Mehta, Luke Rosu, Renata Martins, Eric Goedereis, Sam Insana, Alisa O’Riley, Dave Hannum, Kimberly Foley, Eric Grady, Josh Masse, and Dan Chorney, are just a few of the many people who kept graduate school fun. I couldn't have made it through without you.

To Mom, Dad, and Sara: You have nurtured and supported my educational journey. Thank you for teaching me that I should work with my mind and not with my hands.

To my sisters, Rachel, and Arielle: We've stuck together our entire lives and I'm so proud that we're family. You each mean so much to me and I love you with all of my heart.

Lastly, I would like to send loving thanks to my soon-to-be wife, Kelly Acevedo. She is my best friend and has supported me throughout all of my endeavors. I would not be the man I am today without her love and encouragement. To honor her, I dedicate this dissertation. 


\section{Table of Contents}

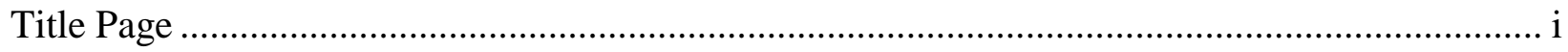

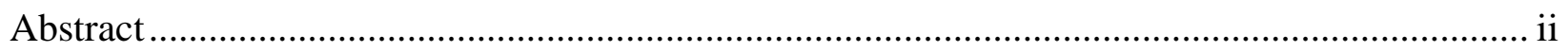

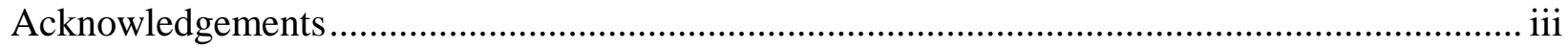

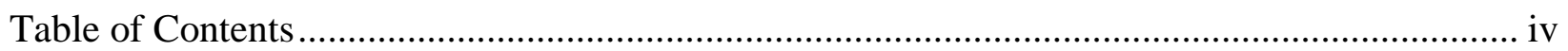

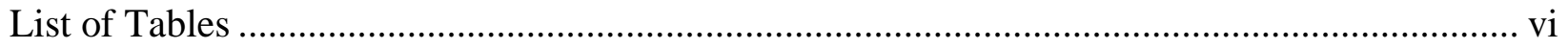

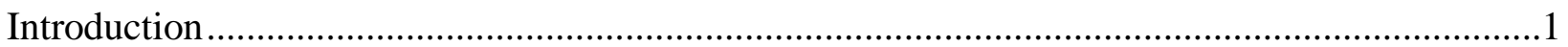

Effects and prevalence of adolescent tobacco use .......................................................

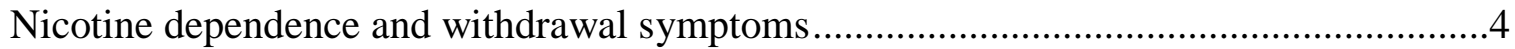

Nicotine withdrawal symptoms as a daily occurrence ............................................6

Nicotine withdrawal symptoms and adolescent smoking cessation .............................8

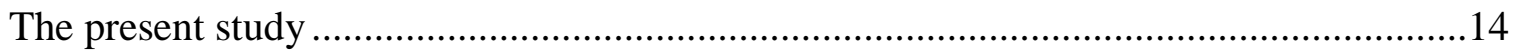

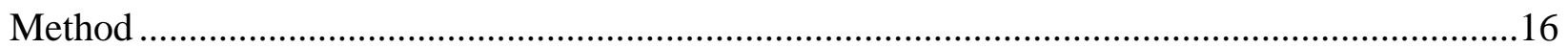

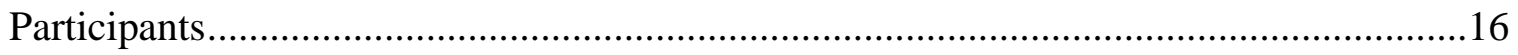

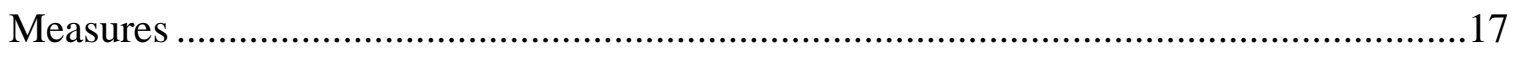

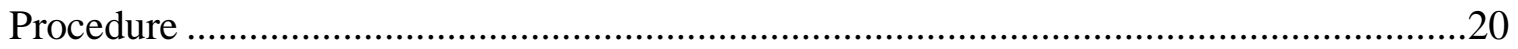

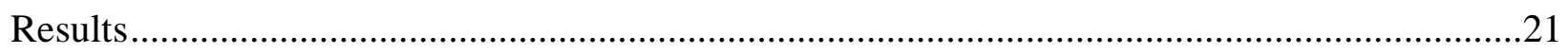

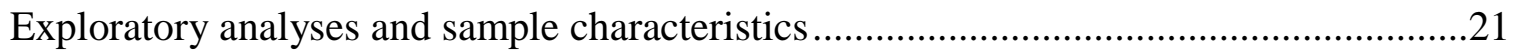

Research Question \#1: What purported nicotine withdrawal symptoms are reported more frequently among adolescent smokers than nonsmokers? ..................................26

Research Question \#2: Does the N-WAY act as a valid assessment of adolescent

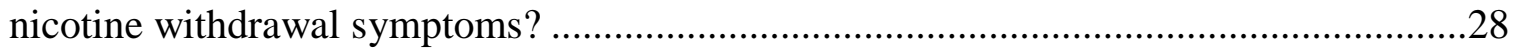

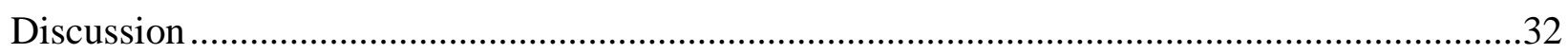

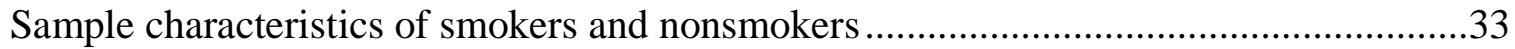


N-WAY and N-WAY Supplement Form differences.

Effect of age and daily caffeine use

Research Question \#1: What purported nicotine withdrawal symptoms are reported more frequently among adolescent smokers than nonsmokers?....

Research Question \#2: Does the N-WAY act as a valid assessment of adolescent nicotine withdrawal symptoms?

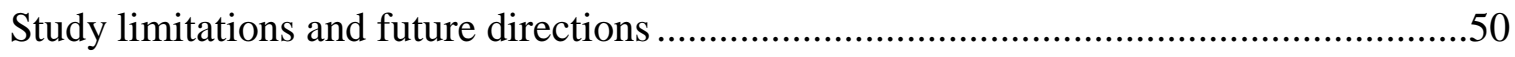

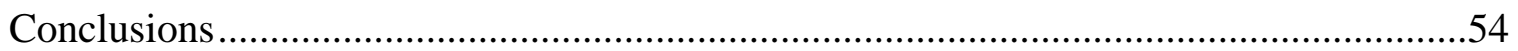

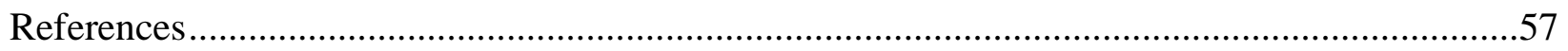

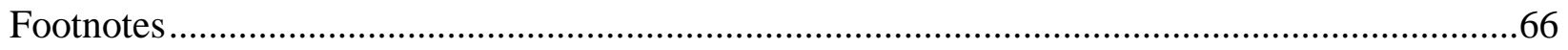

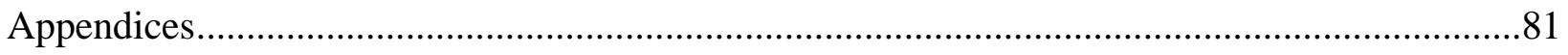

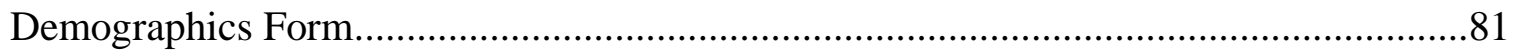

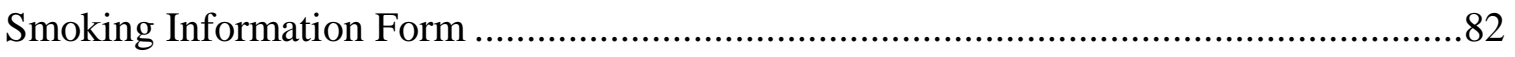

Nicotine Withdrawal Assessment for Youth (N-WAY) ..........................................83

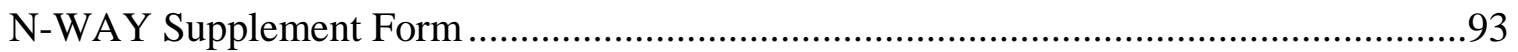

Modified Fagerström Tolerance Questionnaire (mFTQ)..........................................96 


\section{List of Tables}

Table 1. Selected smoker and nonsmokers characteristics

Table 2. Correlations of corresponding N-WAY and N-WAY Supplement Form items among smokers

Table 3. Mean responses of smokers and nonsmokers on N-WAY symptom, N-WAY impact, and N-WAY Supplement Form items.

Table 4. F-values of the effect of age on N-WAY symptom, N-WAY impact, and N-WAY

Supplement Form item differences between smokers and nonsmokers .70

Table 5. Effect size values (partial $\eta^{2}$ ) of N-WAY symptom, N-WAY impact, and N-WAY Supplement Form item differences between smokers and nonsmokers, covarying age

Table 6. F-values of the effect of daily caffeine use on N-WAY symptom, N-WAY impact, and N-WAY Supplement Form item differences between smokers and nonsmokers

Table 7. Effect size values (partial $\eta^{2}$ ) of N-WAY symptom, N-WAY impact, and N-WAY Supplement Form item differences between smokers and nonsmokers, covarying daily caffeine use

Table 8. F-values of N-WAY symptom, N-WAY impact, and N-WAY Supplement Form item differences between smokers and nonsmokers, covarying age and daily caffeine use

Table 9. Effect size values (partial $\eta^{2}$ ) of N-WAY symptom, N-WAY impact, and N-WAY Supplement Form item differences between smokers and nonsmokers, covarying age and daily caffeine use

Table 10. F-values of N-WAY Supplement Form item differences between heavy and light smokers, light and nonsmokers, and heavy and nonsmokers, covarying age and daily caffeine use as necessary.

Table 11. Effect size values (partial $\eta^{2}$ ) of N-WAY Supplement Form item differences between heavy and light smokers, light and nonsmokers, and heavy and nonsmokers, covarying age and daily caffeine use as necessary

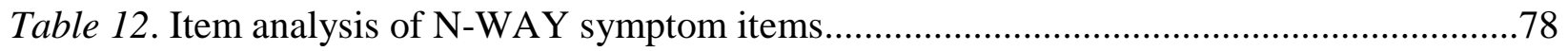

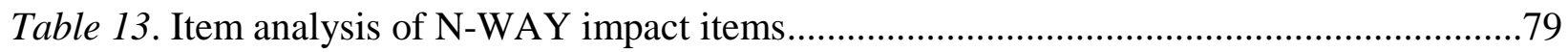

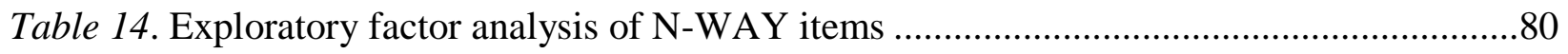


An Examination of Adolescent Nicotine Withdrawal Symptoms:

A Validation of the Nicotine Withdrawal Assessment for Youth

As the most prevalent, preventable cause of death in the United States (McGinnis \& Foege, 1993; United States Department of Health and Human Services [US DHHS], 2004), tobacco use has been estimated to directly lead to nearly half a million annual deaths and costs of $\$ 157$ billion, primarily due to its links to numerous cancers and cardiovascular, respiratory, and reproductive diseases (US DHHS, 2004). Despite these findings, smoking rates among adolescents remain high, as recent data indicate that over $30 \%$ of $12^{\text {th }}$ grade students have smoked a cigarette in the past month (Burns \& Johnston, 2001) and 17\% smoke on a daily basis (Grimshaw et al., 2003). In addition, there has been limited success among smoking cessation programs specific to the adolescent population. Review studies have indicated that most (88\%) adolescents in smoking cessation programs fail in permanently abstaining from cigarette use (Sussman, 2002). Even the most reputable psychosocial interventions for adolescents, such as the Not on Tobacco program, cited by a recent Cochran review (Grimshaw \& Stanton, 2006) as a potentially effective treatment, demonstrate smoking quit rates of less than one-third (Horn, Dino, Kalsekar, \& Mody, 2005). While there has been some progress made in improving the success of long-term smoking cessation among adolescents, there still remains a great deal of room for improvement.

There are a number of explanations for why adolescents begin smoking. The most common reasons include the relaxing effects of smoking, wanting to fit in with friends who smoke, and a desire to portray a certain image (McGee \& Stanton, 1993). The primary explanation for adolescents continuing to smoke involves the combination of pleasurable physiological effects of nicotine and the prevention or alleviation of withdrawal symptoms 
(Benowitz, 1996). Indeed, most teens who smoke regularly report being physically dependent on nicotine and, despite knowledge of the detrimental effects of smoking, are unable to quit (US DHHS, 1994). Nicotine withdrawal symptoms have been cited as a primary reason that smoking behavior is maintained (Centers for Disease Control and Prevention [CDC], 1994; National Institute on Drug Abuse [NIDA], 2006). The Surgeon General indicated that most teen smokers experience withdrawal symptoms and withdrawal symptoms act as a barrier to adolescent smoking cessation and contribute to high relapse rates (US DHHS, 1994). Additionally, preliminary data suggest that one's self-report of severity of withdrawal symptoms may predict cessation success (CDC, 1994). However, despite a strong need to decrease smoking rates and the demonstrated significance of nicotine withdrawal symptoms in quitting success, studies that examine adolescent withdrawal symptoms are scarce. Some difficulty arises from the lack of a widely used assessment for this population. In a review of the adolescent tobacco use literature, Colby, Tiffany, Shiffman, and Niaura (2000) noted that "there is no current 'gold standard' measure of nicotine dependence" (p. 90). Similarly, no well-established or commonly used measurement of adolescent nicotine withdrawal symptoms exists.

Given the current state of the literature, the present study had two primary aims: to further examine the frequency and impact of nicotine withdrawal symptoms in populations of current adolescent smokers and examine the psychometric properties of a new measure of adolescent nicotine withdrawal symptoms. Many of the implications of the preceding goals lie within the realm of improved health outcomes. A better understanding of nicotine withdrawal symptoms may lead to an improved system of identifying adolescents at risk for smoking cessation difficulties and modifying treatment protocol. As the literature demonstrates, withdrawal symptoms play a large role in adolescent smoking cessation failure (CDC, 1994; 
Ershler, Leventhal, Fleming, \& Glyn, 1989; US DHHS, 1994). A necessary step in the examination of the role withdrawal symptoms play in adolescent smoking cessation is the development of an accurate and reliable method of measuring the construct.

\section{Effects and Prevalence of Adolescent Tobacco Use}

In a recent report conducted by NIDA (2006), the adverse health effects of tobacco were found to be primarily responsible for 37 million deaths in the United States. Cigarette smokers were significantly more likely than nonsmokers to develop cancer, lung disease, heart attack, and stroke. Additionally, the negative effects of smoking extend into other domains, such as secondhand smoke, increased risk of asthma, cancer, and cardiovascular disease among children residing with smokers, and a higher rate of residential fires due to dropped cigarettes. Given these dangers, as well as other undesirable effects, $80 \%$ of smokers report a desire to quit; however, only 1 out of every 20 smokers who attempt smoking cessation on their own will succeed (American Psychiatric Association, 2000).

Nicotine, a primary ingredient in tobacco products, has been demonstrated to possess numerous addictive qualities to which many users become dependent, thus impeding smoking cessation (US DHHS, 1988). Following absorption into the blood, nicotine quickly alters hormonal and neurotransmitter functioning, particularly that of dopamine, and leads to numerous pleasurable effects and feelings of euphoria (Benowitz, 1996). Additionally, following ingestion of nicotine, epinephrine and glucose are released into the bloodstream, heart rate and blood pressure increase, and aversive withdrawal symptoms, such as nicotine cravings, irritability, and sleep disturbances, decrease (NIDA, 2006). However, the Surgeon General (US DHHS, 1988) reports that these outcomes weaken with continued use and more nicotine is required to induce similar pleasurable effects over time. In other words, a tolerance develops. Also common among 
frequent smokers are reports of withdrawal symptoms and failed attempts at quitting (US DHHS, 1994). Studies indicate that adolescents become more strongly dependent on nicotine the longer they regularly smoke, decreasing the likelihood of an eventual successful smoking cessation attempt (US DHHS, 1994).

The Surgeon General (US DHHS, 1994) indicated that reducing adolescent tobacco use was of the utmost importance to the country's general health. While there have been general decreases in youth smoking prevalence since reaching a high in the mid-1990s, the decline has slowed as of late (NIDA, 2006) and an equal number of adolescents are trying cigarettes for the first time as in previous years (Office of Applied Studies, 2006). In addition to an increased likelihood of smoking as an adult (US DHHS, 1994), there are additional negative health effects of tobacco use unique to young smokers. The Surgeon General (US DHHS, 1994) stated that during one's youth, smoking is likely to lead to poor lung growth and capacity, respiratory problems, and general poor physical health. According to the most recent figures from the Office of Applied Studies (2006), 13\% of 12-17 year old adolescents use tobacco, with cigarettes (11\%) the most commonly used product. Other estimates indicate a higher smoking occurrence among older adolescents, ranging from 23-30\% among $12^{\text {th }}$ graders (Burns \& Johnston, 2001; Johnston, O'Malley, Bachman, \& Schulenberg, 2005). Prevalence rates for adolescent (12-17 years of age) cigarette use are fairly constant across gender, but moderately vary based upon racial background, with $13 \%$ of Caucasians, $9 \%$ of Latinos, and $7 \%$ of African-Americans reporting smoking in the past month (Office of Applied Studies, 2006).

\section{Nicotine Dependence and Withdrawal Symptoms}

Nicotine dependence refers to sustained nicotine use despite clinically significant impairment occurring as a result (American Psychiatric Association, 2000). Additional 
symptoms of nicotine dependence include an increased nicotine tolerance, failed quit attempts, more nicotine use than initially planned, and withdrawal symptoms. Withdrawal symptoms occur following cessation or diminished use and are identified by aversive physical, psychological, or emotional symptoms (American Psychiatric Association, 2000). The most common nicotine withdrawal symptoms include nicotine cravings, sleep problems, and irritability, with less frequent reports of anxiety, depression, poor concentration, weight gain, and decreased heart rate (Henningfield, 1995). These symptoms are clearly instrumental in sustaining smoking behavior, as a majority of users report smoking as a vehicle to prevent or alleviate withdrawal symptoms, particularly after prolonged periods without nicotine (American Psychiatric Association, 2000). In large-scale surveys querying the withdrawal symptoms of adolescent smokers during their last quit attempt (Rojas, Killen, Haydel, \& Robinson, 1998), tobacco cravings (45\%) were the most frequently reported, followed by anxiety/tension (32\%), restlessness (29\%), irritability (29\%), hunger (25\%), poor concentration (22\%), depression (15\%), and sleep difficulties (13\%). The authors report that a further examination of the nicotine withdrawal symptoms of adolescents is necessary in order to better understand their role in smoking cessation.

The distinction between nicotine dependence and withdrawal symptoms is an important one. While withdrawal symptoms are a byproduct of dependence, the two represent separate constructs. Most of the adolescent smoking literature examines withdrawal symptoms within the context of dependence, or as it is often referred, addiction. In a recent review, Kassel (2000) reported only one study dedicated exclusively to adolescent nicotine withdrawal symptoms compared to substantially more investigations of adolescent nicotine dependence. Given the state of the literature, it is often difficult to parcel out findings regarding the effects of withdrawal symptoms from those of dependence. The two terms are often used interchangeably and the same 
conclusions are assumed to apply to both. However, a number of studies (Colby et al., 2001; Kassel, 2000; Sussman, 2002) have called for a more focused study of nicotine withdrawal symptoms. In addition, review papers (Colby et al., 2001; Collins \& Graham, 2002) have criticized prior studies examining nicotine withdrawal symptoms in adolescents for certain methodological weaknesses, such as the use of a retrospective design, where adolescents are queried about withdrawal symptoms experienced in the past.

Another notable absence in the study of nicotine dependence and withdrawal symptoms is a universally accepted measure of either (Colby et al., 2001). Three primary measures are typically found in studies examining adolescent smokers, all of which aim to measure nicotine dependence: (1) a modified version of the Fagerström Tolerance Questionnaire (mFTQ; Prokhorov, Pallonen, Fava, Ding, \& Niaura, 1996) ${ }^{1}$, (2) The Hooked on Nicotine Checklist (DiFranza et al., 2002a), and (3) diagnostic criteria from the Diagnostic and Statistical Manual of Mental Disorders (DSM-IV; American Psychiatric Association, 2000) for nicotine dependence. However, despite the strengths and weaknesses of each of these measures, there is still the need for the creation and use of a measure of nicotine withdrawal symptoms for adolescents. The above-mentioned assessments are predominantly aimed to evaluate nicotine dependence, not necessarily withdrawal symptoms. These measures may detect physical dependence, but have little relevant information regarding if an adolescent is experiencing withdrawal symptoms and to what extent. Again, while nicotine dependence and withdrawal symptoms are interrelated, as withdrawal symptoms are indicative of dependence, each refers to its own distinct construct. Nicotine Withdrawal Symptoms as a Daily Occurrence

The half-life of nicotine is about two hours (Benowitz, 1996). As such, it is possible, depending on when and how often one smokes, that nicotine levels can decrease to the point 
where withdrawal symptoms occur on a day-to-day basis for regular smokers. In other words, a quit attempt may not be a prerequisite for experiencing withdrawal symptoms. Smokers often report withdrawal symptoms when they awake, as smoking abstinence has occurred during sleep and nicotine levels in the body have decreased (Heatherton, Kozlowski, Frecker, \& Fagerström, 1991). There are estimates that after only a few hours without a cigarette, smokers experience nicotine withdrawal symptoms (NIDA, 2006).

Limited studies have reviewed the early patterns of withdrawal symptoms, but initial evidence implies that the latency to withdrawal, or amount of time without smoking a cigarette prior to experiencing nicotine withdrawal symptoms, is less for more frequent adolescent smokers (DiFranza \& Ursprung, 2008). Heavier smoking adolescents reported significantly higher rates of nicotine withdrawal symptoms (impatience, strong urges to smoke, losing temper, poor concentration, and nervousness) when not smoking for an extended period of time than adolescents smoking less frequently (DiFranza \& Ursprung, 2008). Hendricks, Ditre, Drobes, and Brandon (2006), calculated that heavy adult smokers begin experiencing their first withdrawal symptoms only 30 minutes after their last cigarette. During this time, abstaining smokers exhibited more cigarette cravings and poorer reaction time than smokers permitted to smoke freely. After 60 minutes, abstaining smokers reported higher rates of anger and a decreased heart rate than smokers permitted to smoke freely. After 180 minutes, nearly all withdrawal symptoms measured (cigarette cravings, anger, anxiety, difficulty concentrating, and sadness) were found at elevated rates in abstaining smokers. Considering the likely restrictions on when and where teens can smoke-high schools commonly ban smoking (Wakefield et al., 2000), for instance — and that latency to withdrawal has been measured to be as brief as 30 
minutes, it is likely that at least some adolescent smokers experience day-to-day withdrawal symptoms, even in the absence of a cessation attempt.

\section{Nicotine Withdrawal Symptoms and Adolescent Smoking Cessation}

Despite the health risks and societal cost of tobacco use, "few serious attempts have been made to document nicotine dependence among adolescents" (Kassel, 2000, p. 28). The void in the literature is particularly apparent when compared to the more frequent analysis of adult smokers (Kassel, 2000). However, there remains a number of findings in this area that have been well established. First is the consistent documentation that adolescent smokers report symptoms of nicotine dependence and withdrawal symptoms. Secondly, an overwhelming majority, although not as much as adults (CDC, 2008), of adolescents who attempt to quit smoking fail and symptoms of withdrawal have been cited as a barrier to successful smoking cessation. Lastly, studies (e.g., Colby et al., 2000; Horn, Fernandes, Dino, Massey, \& Kalsekar, 2003) cite the need to develop accurate assessments of adolescent nicotine dependence and withdrawal symptoms and the integration of this knowledge into smoking cessation treatment programs.

A number of studies (e.g., DiFranza et al., 2002b; O’Loughlin et al., 2003; Prokhorov et al., 2001) have demonstrated that adolescents exhibit symptoms of nicotine dependence and withdrawal that broadly resemble those observed in adults, but differences have arisen between the two populations. Prokhorov and colleagues (1996) compared the smoking characteristics of samples of adults and adolescents in grades 10-12 and found differences in smoking preferences and severity of nicotine dependence. For instance, adolescents reported smoking considerably fewer daily and weekly cigarettes than adults - only about one-third the amount. Moreover, while about half of adults in the study were classified as highly dependent on nicotine, only $20 \%$ 
of adolescents were highly nicotine dependent. Adolescents also reported lower rates of always inhaling, smoking soon after awaking, and smoking when sick.

Following an examination of adolescent smoking habits over the course of 30 months, DiFranza and colleagues (2002b) found that the development of nicotine dependence often occurs quickly and following only moderate use. For instance, among adolescents reporting symptoms of nicotine dependence, $52 \%$ experienced symptoms when smoking only about 2 weekly cigarettes and $65 \%$ among those smoking one cigarette a day. Furthermore, the selfreport of only one symptom of nicotine dependence was predictive of sustained future smoking behavior. As is commonly observed among young smokers, very few were heavy smokers. The first symptoms of nicotine dependency were often documented to occur within the first weeks or even days of sporadic, and far before daily, smoking (DiFranza et al., 2002b). These results demonstrate how quickly adolescents become dependent on nicotine and after relatively infrequent tobacco use.

DiFranza and colleagues (2000) hypothesized that the development of nicotine withdrawal symptoms occurs in an ideographic fashion. Put simply, there is variability in determining if and when an adolescent will become dependent on nicotine. The authors suggested that some smokers become dependent on nicotine quickly, others slowly, and yet some appear to be resilient to nicotine addiction. If these three categorizations do indeed exist, then there is a clear need for accurate measurements of one's nicotine dependency. Similar findings have been documented by O'Loughlin et al. (2003). Adolescents who reported smoking for only a short period of time experienced symptoms of nicotine dependence and cravings while still smoking. These findings denote that a long history of every day smoking is not a requisite for the development of nicotine withdrawal symptoms. The authors recommend that treatment programs 
aimed at reducing adolescent tobacco use take into consideration nicotine dependence and withdrawal symptoms, particularly as they relate to sustained smoking behavior.

Other studies have provided further links between symptoms of nicotine withdrawal and smoking cessation. For instance, Prokhorov and colleagues (2001) investigated the readiness to quit among current and former adolescent smokers. The authors found that an elevated severity of withdrawal symptoms was reported at higher rates among current smokers during prior quit attempts than successful quitters. This finding suggests that nicotine withdrawal symptoms deter act as a barrier for successful smoking cessation. In general, Prokhorov et al. (2001) demonstrated a relation between higher rates of nicotine withdrawal symptoms and lower rates of smoking cessation success among adolescent smokers.

Further supporting the relation of withdrawal symptoms to quitting success are the findings of a large-scale CDC (1994) survey. From a sample size of over 2,500 adolescents and young adults with a history of tobacco use, it was clear that youths experienced symptoms of nicotine withdrawal during periods of smoking abstinence and these symptoms both impede quitting success and facilitate continued smoking behavior. For instance, among 10-18-year old smokers with the highest rate of monthly cigarette use, $74 \%$ reported that difficulty quitting was a reason for continued smoking. Nearly all (93\%) current adolescent daily smokers conveyed at least one nicotine withdrawal symptom during smoke-free periods, indicating that nicotine withdrawal symptoms are nearly universal for smokers. When comparing the withdrawal symptoms of youths who were successful quitters of tobacco to those of current smokers, differences in the experience of withdrawal symptoms arose. While $66-93 \%$ of current adolescent smokers, regardless of frequency of use, reported at least one nicotine withdrawal symptom during prior quit attempts, only $44 \%$ of former smokers (i.e., successful quitters) 
reported such symptoms upon prior smoking cessation incidents. While the findings of the CDC (1994) and Prokhorov and colleagues (2001) are persuasive, they are limited by the accuracy of the participants' memories, as the studies' retrospective designs called for participants to recall dependence and withdrawal symptoms from past months or even years. Nevertheless, these studies demonstrate that the nicotine withdrawal symptoms associated with smoking cessation likely contribute to the continued use of tobacco.

McNeill, West, Jarvis, Jackson, and Bryant (1986), in one of the few studies to exclusively examine nicotine withdrawal symptoms in adolescents, found that most adolescent smokers experience withdrawal symptoms, such as cravings, hunger, irritability, and restlessness, during quit attempts. Within a sample of female adolescent smokers, participants retrospectively reported their withdrawal symptoms during past smoking cessation attempts. Higher rates of withdrawal symptoms were associated with more frequent use, with $74 \%$ of daily smokers acknowledging some symptoms of nicotine withdrawal. Once again, high rates of failure $(71 \%)$ were associated with adolescents attempting smoking cessation. McNeill and colleagues (1986) concluded that adolescents experience nicotine withdrawal symptoms and these symptoms positively correlate with higher rates of smoking.

Horn et al. (2003) also evaluated the relations among smoking behavior, withdrawal symptoms, and smoking cessation success. Approximately $80 \%$ of adolescents in a smoking cessation program were found to be moderately, highly, or very highly dependent on nicotine prior to quitting. While smoking frequency and duration were positively correlated with reports of nicotine dependence, some adolescents — about a fifth—reported few symptoms of nicotine dependence. Adolescents who were less nicotine dependent were more likely to successfully quit smoking than those with higher rates of dependency. As the authors note, "[t]here is a paucity of 
research using ...nicotine dependence assessments among adolescent smokers" (p. 770). Despite clear indications of the impact of adolescent nicotine dependence and withdrawal symptoms on smoking cessation success, an established assessment of these constructs continues to be absent.

Killen and colleagues (2001) studied the withdrawal symptoms of adolescents upon smoking cessation. Similar to adults, a decrease in heart rate and ability to focus were observed along with increases in nicotine cravings, drowsiness, frustration, anxiety, and restlessness. Furthermore, these symptoms were subjectively measured as moderate in intensity, similar to adults. However, differences between age groups emerged when some adolescents used a nicotine patch. Nicotine replacement therapy (i.e., nicotine patch) did not appear to alleviate several withdrawal symptoms, such as cravings, restlessness, and anxiety, contrary to findings with adult populations. In other words, youths using a nicotine patch reported similar withdrawal symptoms as those with a placebo patch. Conversely, in studies of the adult population, the nicotine patch has been consistently demonstrated to be an effective smoking aid in reducing nicotine withdrawal symptoms (Lancaster, Stead, Silagy, \& Sowden, 2000). When taken together, these results indicate that the role of nicotine may differ in some ways between adolescents and adults. Adolescents may experience certain symptoms of withdrawal simply as a product of adolescence, independent of nicotine intake.

Prokhorov, Hudmon, Cinciripini, \& Marani (2005) further investigated this theory and found that some withdrawal symptoms of former smokers thought to occur as a result of nicotine use, such as irritability, restlessness, trouble sleeping, trouble concentrating, increased hunger/weight gain, and feeling depressed, did not differ among light and never smokers. In other words, certain symptoms, often attributed to nicotine withdrawal, may be common in all adolescents, regardless of whether they smoke. In addition, never smokers reported more sleep 
problems than light smokers, directly contradicting previous reports of sleeping problems as a nicotine withdrawal symptom (American Psychiatric Association, 2000). Although Prokhorov et al. (2005) did find more pronounced differences between heavy and nonsmokers in their report of cravings, irritability, restlessness, trouble concentrating, and increased hunger/weight gain, the lack of differences between light and nonsmokers indicates that not all nicotine withdrawal symptoms are necessarily a result of smoking cessation. It appears that, to some extent, certain purported nicotine withdrawal symptoms occur in nonsmokers, and can be attributed to a normative adolescent experience. Given that most adolescent smokers smoke occasionally and would be categorized as light smokers (Prokhorov et al., 1996), there is a need for a group of similarly-aged nonsmokers to be used as a basis for comparison in studies of adolescent nicotine dependence and withdrawal symptoms. Although the absence of a nonsmoking comparison group does not discredit the results of other studies on this topic, the presence of such participants acts as a control group of sorts, better evaluating the source of various withdrawal symptoms.

As is demonstrated from prior studies, there are indications that nicotine dependence and withdrawal symptoms occur in adolescent smokers and serve as a barrier to successfully quitting. In a review of 66 adolescent tobacco cessation trials, Sussman (2002) concluded that, as a whole, treatment programs averaged a $12 \%$ quit rate. While Sussman noted that these interventions improve the likelihood of smoking cessation over no program at all, she notes that additional treatment services for teens physically addicted to nicotine is needed. This recommendation is reiterated by other experts in this field. Kassel (2000) notes that nicotine dependence and withdrawal symptoms do not occur at the same rate for all adolescents and treating all smokers in the same way is an egregious error. In other words, treatments should be modified based upon 
the presenting withdrawal symptoms of the smoker. However, in the absence of an established nicotine withdrawal measure, it becomes difficult to accurately or reliably evaluate the construct of nicotine withdrawal symptoms in adolescents.

\section{The Present Study}

Given the potential role of nicotine withdrawal symptoms in smoking cessation, there is a need to better assess these symptoms within the adolescent population. This study examined nicotine withdrawal symptoms in current adolescent smokers and aimed to validate a measure of adolescent nicotine withdrawal symptoms. Through the inclusion of both smoking and nonsmoking adolescent samples, the withdrawal symptoms of nicotine use were more accurately distinguished from those occurring in the adolescent population at large, regardless of smoking status. Considering the limitations in studying youth nicotine withdrawal symptoms in the absence of a comprehensive measure of the construct, the reliability and validity of a new assessment was also examined.

The first goal of the present study was the examination of current nicotine withdrawal symptoms in a sample of current adolescent smokers. Through the prospective monitoring of day-to-day nicotine withdrawal symptoms, information was revealed about the frequency and impact of a number of potential withdrawal symptoms. The present study assessed the frequency and impact of nicotine withdrawal symptoms among smokers and nonsmokers. As Prokhorov et al. (2005) was the only study found that utilized a nonsmoking adolescent comparison group, this methodological detail was duplicated. The second goal of the present study was to evaluate the psychometric properties of the Nicotine Withdrawal Assessment for Youth (N-WAY; Horn, in preparation), a measure of nicotine withdrawal symptoms for adolescents in the process of a 
cessation attempt. Its reliability, validity, and ability to accurately discriminate between adolescent smokers and nonsmokers were investigated.

The N-WAY was developed in several stages. Following a literature review, a preliminary listing of documented nicotine withdrawal symptoms was established. Content validity was later evaluated using methods advocated by Lawshe (1975), where 10 established researchers within the areas of nicotine dependence, withdrawal symptoms, and adolescent smoking cessation rated each preliminary N-WAY item on the basis of its saliency in measuring adolescent nicotine withdrawal symptoms. Using a content validity ratio to determine the agreement among raters in determining the necessity of each item, items with sufficient levels of agreement remained in the final N-WAY version. Four constructs were hypothesized to be assessed by the N-WAY: physical nicotine withdrawal symptoms, emotional nicotine withdrawal symptoms, the impact of physical symptoms, and the impact of emotional withdrawal symptoms.

The N-WAY differs from other established measures of nicotine dependence in three principal ways. First, the N-WAY is a measure of nicotine withdrawal symptoms, rather than nicotine dependence, which most other measures assess. As discussed earlier, this is a critical distinction. Second, the symptoms queried were designed by researchers to specifically apply to adolescent nicotine withdrawal. Given the differences between adolescent and adult patterns of smoking and experience of nicotine dependence symptoms (Mermelstein, 2003), an assessment suited to measure adolescent nicotine withdrawal symptoms would likely be more accurate than one constructed for use with all ages. Where the modified Fagerström Tolerance Questionnaire (mFTQ; Prokhorov, et al., 1996), or other similarly validated measures, may be helpful in determining if one is dependent on nicotine, the N-WAY, on the other hand, is designed to detect the frequency and impact of nicotine withdrawal symptoms. Third, the N-WAY may be a more 
comprehensive measure of adolescent nicotine withdrawal symptoms than current available assessments. In addition to the common symptom of cravings to smoke, the N-WAY also queries a more comprehensive range of symptoms, such as headaches, dizziness, and conflict with others. These less frequent symptoms are typically not queried by other measures of nicotine dependence, many of which are fairly brief (e.g., 10 questions or less).

Although utilizing a sample of smokers engaging in a quit attempt, rather than current smokers, may admittedly lead to more severe nicotine withdrawal symptoms (Morrell, Cohen, \& al'Absi, 2008), there are indications that current smokers experience day-to-day withdrawal symptoms in the absence of a cessation attempt. Estimates among heavy daily smokers indicate that withdrawal symptoms arise anywhere from 30 minutes to a few hours without a cigarette (Hendricks et al., 2006; NIDA, 2006). While it is possible that certain smokers may prevent any withdrawal symptoms from occurring by smoking proactively, it is hypothesized that current adolescent smokers, to some extent, experience withdrawal symptoms. Thus, the results of the present study are likely to be a conservative estimate of the frequency and impact of adolescent nicotine withdrawal symptoms, as more symptoms would likely arise by restricting participants' consumption of nicotine over a long period of time (Killen et al., 2001; McNeill et al., 1986; Rojas et al., 1998).

Method

\section{Participants}

Participants, ranging in age from 13-19 years old were recruited for the study through community and high school advertisements and word of mouth. Exclusion criteria included current enrollment in college. Forty-three current smokers (24 female, 19 male) and 50 nonsmokers (29 female, 21 male) participated in the study. The mean age of smokers was 17.2 
years old (Range $=14-19$ years old) and 84\% were Caucasian, 9\% African-American, 2\%

Hispanic, 2\% Indian, and 2\% Native American. The mean age of nonsmokers was 16.2 years old $($ Range $=13-19$ years old $)$ and 90\% were Caucasian, 4\% African-American, 4\% Hispanic, and $2 \%$ Indian. Nearly all of smokers (93\%) and some of nonsmokers (38\%) resided in West Virginia. Nine additional states were represented in the total sample.

Participants were classified as cigarette smokers or nonsmokers based upon their selfreported response to the question "Do you smoke almost every day?" on the Smoking Information Form. Participants reporting smoking cigarettes almost every day were considered to be smokers. Likewise, adolescents who reported not smoking in the past year were classified as nonsmokers. Exclusion criteria included smoking cessation or onset during study participation and, for nonsmokers, the use of cigars or chewing tobacco. Dropout rates between the first and second administration of the measures were considerable. Smokers were far more likely to drop out than nonsmokers. Over half (53\%) of smoking participants did not fully complete the study, compared to $14 \%$ of nonsmokers. In all cases of dropout, the participant did not return the second set of mailed questionnaires. No participant actively withdrew his or her consent.

\section{Measures}

Demographics form. At the onset of the study, a Demographics Form (refer to Appendix A) was administered to gather information about participants' gender, age, race, grade in school, city and state of residence, household members who smoke, and secondhand smoke exposure outside the home.

Smoking Information Form. Largely derived from a standard form administered to adolescents in studies involving the Not on Tobacco smoking cessation program (e.g., Dino, Kamal, Horn, Kalsekar, \& Fernandes, 2004), the Smoking Information Form (refer to Appendix 
B) assessed participants' smoking history and frequency. Additional questions inquired about prior quit attempts and use of smokeless tobacco, cigars, and caffeine.

The Nicotine Withdrawal Assessment for Youth (N-WAY). The N-WAY (Horn, in preparation; refer to Appendix C) is a 20-item measure designed for youths 13-19 years old that is theorized to evaluate the frequency and impact of various purported nicotine withdrawal symptoms experienced over the past week. The N-WAY was originally designed to be used with adolescents in the process of quitting smoking and symptom frequency is compared to "as usual" occurrence. Symptoms comprising the measure include: restlessness, anger, headaches, concentration problems, alertness, fatigue, stress, hyperactivity, depression, nervousness, dizziness, sleep disturbances, irritability, hunger, difficulty falling asleep, conflict with family, friends, and school staff, and nicotine cravings. Items are formatted in a multiple choice format resembling a 5-point Likert scale. Each N-WAY symptom and impact item was scored 1-5, based upon the participant's response, with higher scores ascribed to higher frequency or impact. For symptom items: $1=$ Rarely, $2=$ Somewhat less than usual, $3=$ About the same as usual, $4=$ Somewhat more than usual, and $5=$ Much more than usual. Impact items were scored: $1=$ Not at all, $2=$ A little, $3=$ Somewhat, $4=$ A lot, and $5=$ Extremely. With these numerical figures, a total symptom and impact score was calculated, by summing all of the respective 19 items. The $20^{\text {th }} \mathrm{N}$-WAY item queries time of last cigarette and is not directly scored.

$N$-WAY Supplement Form. Considering that the N-WAY was designed to be used with adolescents in the process of smoking cessation, its phrasing solicits participants to select if symptoms occur more, less, or the same as usual. It was hypothesized that this phrasing may lead to inaccurate results when administered to current smokers, whose withdrawal symptoms may occur frequently, but the same "as usual." In order to improve the accuracy of responses, the N- 
WAY Supplement Form (refer to Appendix D) was administered in order to more objectively assess the frequency of purported nicotine withdrawal symptoms in current smokers. The NWAY Supplement Form included the same symptoms, but participants reported how often symptoms occurred. Similar to the N-WAY, each N-WAY Supplement Form item was scored from 1-5, where: $1=$ Not at all, $2=$ A little, $3=$ Sometimes, $4=$ A lot, and $5=$ Almost always. A total N-WAY Supplement Form score was calculated by summing each of the 19 items.

Modified Fagerström Tolerance Questionnaire (mFTQ). The mFTQ (Prokhorov et al., 1996; refer to Appendix E) is a seven-item multiple choice questionnaire that has been demonstrated to evaluate nicotine dependence in adolescent smokers. It queries respondents on: number of daily cigarettes smoked, frequency of inhalation, time of first cigarette of the day, favorite time to smoke, difficulty with brief smoking abstinence, smoking when sick, and morning smoking habits. Respondents are scored on a scale of 1-9, with higher scores indicative of more severe dependence. Scores ranging from 0-2 indicate no nicotine dependence, 3-5 moderate dependence, and 6-9 high dependence. Studies of the mFTQ have found acceptable levels of validity and reliability. For instance, Prokhorov et al. (2000) and Wellman et al. ( 2006) established a satisfactory range of internal consistency (Cronbach's $\alpha=.70-.83$ ). Adequate concurrent validity has also been found with saliva cotinine ( $r=.40$; Prokhorov et al., 2000). Test-retest reliability taken at a two month interval $(r=.71)$ indicates acceptable reliability as well (Prokhorov, Koehly, Pallonen, \& Hudmon, 1998). These statistics indicate that the mFTQ satisfactorily assesses nicotine dependence in an adolescent sample. Additionally, reviews of the literature indicate that the mFTQ is the most widely used measure to assess nicotine dependence in adolescents (Kassel, 2000). The mFTQ best applied to the present study as it has been established for use in 14-20 year old adolescents, which is most similar to the 13-19 age range of 
the N-WAY. Another commonly used measures of nicotine dependence, the Hooked on Nicotine Checklist (DiFranza et al., 2002a), was considered, although it has only been validated with adolescents between ages 12 and 15 .

\section{Procedure}

Upon expressing interest in advertisements for the study, the participant and, if the adolescent was under 18, his or her parent, was sent a consent form. Following the signing of the consent form(s), participants completed a series of questionnaires, administered in-person or through the mail. In the case of mailed administration, self-addressed, stamped envelopes were provided. No specific instructions were given to smokers to continue or quit smoking during the study. At the onset of the study, all participants were administered the Demographics Form, Smoking Information Form, N-WAY, and N-WAY Supplement Form. Given that the mFTQ items pertain exclusively to smoking behavior (e.g., morning smoking), only smokers completed the measure. Participants were mailed a second set of measures one week later. All of the above questionnaires, except the Demographics Form, were mailed to the participants to complete. In exchange for their participation, adolescents received \$20 in gift cards to a national retailer, paid in $\$ 10$ increments following the return of each set of measures. There was no penalty for withdrawing from the study.

\section{Results}

Unless specified otherwise, all results are gathered from the first administration of the measures.

\section{Exploratory Analyses and Sample Characteristics}

Missing data imputation. Missing data (i.e., leaving an item blank) were imputed using a mean substitution method, where the item's mean, among the smoking or nonsmoking sample, 
based upon the participant's smoking status, replaced the missing item. This method of data imputation is found to be superior than more traditional methods of handling missing data, such as listwise deletion, which can lead to misleading results (King, Honaker, Joseph, \& Scheve, 1998) and remove large portions of useful data (Duncan, Duncan, \& Strycker, 2006). Mean substitution, on the other hand, imputes the sample mean and is a relatively conservative estimate that does not alter the distribution of the data (Tabachnick \& Fidell, 1996). Less than $1 \%$ of data was considered missing.

Smoker and nonsmoker sample differences. A one-way analysis of variance (ANOVA) was performed to examine initial differences between the smoking and nonsmoking samples. Table 1 illustrates general smoker and nonsmoker characteristics. Smokers were significantly older than nonsmokers, $F(1,92)=9.44, p \leq .01$, with mean ages of 17.2 and 16.2 years, respectively (the effects of this difference will be discussed in more detail below). Smoking teens were more likely to reside with a household member who smokes, $\chi^{2}(1)=19.47, p \leq .01$, with $65 \%$ of smoking teens having at least one household member who smokes, compared to $22 \%$ of nonsmoking teens. Similarly, smokers also reported being regularly exposed to secondhand smoke outside the home more frequently than nonsmokers, $\chi^{2}(1)=42.40, p \leq .01$, at rates of $81 \%$ and $14 \%$, respectively. Smokers and nonsmokers also differed on their daily consumption of caffeinated beverages. Smokers reported drinking more servings of caffeine (e.g., 12 oz. soda, 8 oz. of coffee) than nonsmokers, $F(1,92)=15.80, p \leq .01$, at rates of 3.1 and 1.3 drinks per day, respectively.

Sample characteristics of smokers. Smoking participants $(n=43)$, reported smoking about a half a pack of cigarettes during a typical weekday $(M=10.7$ cigarettes, $S D=11.0)$ and about a pack on a typical weekend $(M=19.0$ cigarettes, $S D=15.4)$. Smokers averaged a 
relatively long history of smoking (at least one cigarette a month), with a mean of 32.5 months $(S D=26.9$ months $)$. Additionally, many teen smokers had made prior attempts at smoking cessation, with $44 \%$ of sample smokers reporting at least one prior quit attempt. Twenty-three percent of smokers reported using smokeless tobacco in the past 30 days and $30 \%$ using cigars. Although smokers who used smokeless tobacco or cigars smoked a statistically equal amount of cigarettes than only-cigarette smokers, analyses indicated that there were some significant differences between these subsets of smokers. On the N-WAY, smokeless tobacco users reported lower rates of feeling tired, $F(1,42)=4.30, p<.05$, and irritability, $F(1,42)=5.30, p<.05$, than smokers who did not use smokeless tobacco. Smokers who used smokeless tobacco, however, reported more conflict with school staff, $F(1,42)=4.31, p<.05$, on the N-WAY Supplement Form and were classified as being more nicotine dependent on the mFTQ, $F(1,42)=4.21, p<$ .05 , than smokers who did not use smokeless tobacco.

Cigarette smokers who also smoked cigars in the past 30 days reported lower rates of feeling tired, $F(1,42)=5.70, p<.05$, on the N-WAY and higher rates of feeling hungry, $F(1,42)$ $=4.44, p<.05$, on the N-WAY Supplement Form than cigarette smokers who did not smoke cigars. A linear regression demonstrated that time of last cigarette predicted mFTQ total score, $F(1,42)=7.38, p \leq .01, R^{2}=.16$, and category of nicotine dependence, $F(1,42)=7.74, p \leq .01$, $R^{2}=.16$, with a more recent smoked cigarette linked to a more severe nicotine dependence. There relations between total daily cigarettes smoked and time of last cigarette was not significant, $F(1,42)=3.65, p=.06, R^{2}=.09$.

Participant dropout characteristics. As part of the study's procedure, participants were mailed a second set of measures one week after completing the first set of questionnaires. Smokers $(53 \%)$ were significantly more like to dropout than nonsmokers $(14 \%), F(1,92)=$ 
$19.62, p \leq .01$. Considering this uneven split, comparisons of participants who dropped out to those remaining in the study were conducted. Dropouts were found to be more likely to smoke regularly, $F(1,92)=19.62, p \leq .01$, and smoke more weekday, $F(1,92)=10.22, p \leq .01$, and weekend cigarettes, $F(1,92)=9.86, p \leq .01$, than study completers. In order for a more detailed analysis, smoking and nonsmoking dropouts were compared to smoking and nonsmoking participants who remained in the study, respectively.

Smokers who dropped out $(n=23)$ differed from smokers completing the study $(n=20)$ on only one item, the impact of hunger, $F(1,42)=6.08, p<.05$, with dropouts reporting a higher impact. No other significant differences on total scores or individual items were found on the Smoking Information Form, N-WAY, N-WAY Supplement Form, or mFTQ. Nonsmokers who dropped out $(n=8)$, in comparison to nonsmokers completing the study $(n=42)$, were found to report significantly more household members who smoke, $F(1,49)=4.93, p<.05$, less impact of trouble concentrating, $F(1,49)=4.77, p<.05$, and lower rates of feeling tired on the N-WAY Supplement Form, $F(1,49)=5.24, p<.05$.

$N$-WAY and N-WAY Supplement Form differences. Paired samples t-tests were conducted in order to assess differences between the responses of smokers on corresponding N-WAY and N-WAY Supplement Form items. The total N-WAY symptom $(M=50.27)$ and N-WAY Supplement Form $(M=50.93)$ score were significantly correlated, $r=.77, p \leq .01$. Table 2 demonstrates significant moderate to strong correlations for 17 of 19 parallel items among smokers (Range $=.32-.80)$. Two items, "I was alert," $r=.27, p=.08$, and "I was tired," $r=.18$, $p=.24$, did not demonstrate significant correlations between the N-WAY and N-WAY Supplement Form responses. Among nonsmokers, the total score of each form was strongly 
correlated, $r=.81, p \leq .01$ and all corresponding N-WAY and N-WAY Supplement Form items were significantly correlated with one another, with all correlation coefficients above .50 .

\section{Reports of Nicotine Withdrawal Symptoms Among Smokers and Nonsmokers. Mean} scores of smokers' and nonsmokers' N-WAY and N-WAY Supplement Form are presented in Table 3 to demonstrate initial differences. However, considering the significant differences in the ages and daily caffeine consumption of smokers and nonsmokers, these variables were covaried in order to best reflect group differences.

Effect of age on nicotine withdrawal symptoms. Smoking participants were, on average, one year older than nonsmoking participants. Among smokers, age was not significantly correlated with number of daily cigarettes smoked, $r=-.04, p=.82$. A one-way analysis of covariance (ANCOVA) was performed, with age as a covariate, to better understand the effect of age on purported nicotine withdrawal symptoms. Tables 4 and 5 illustrate the findings and effect size, respectively, from the ANCOVA and indicates that age had a significant effect on the total variance of N-WAY symptom score, $F(1,92)=4.94, p<.05$, partial $\eta^{2}=.05$. Nevertheless, there remained a significant difference and a larger effect due to smoking status on this scale, $F(1,92)$ $=16.73, p \leq .01$, partial $\eta^{2}=.16$. Similar findings were drawn with regard to total N-WAY impact score and N-WAY Supplement Form score. Age had a significant effect on total N-WAY impact score, $F(1,92)=6.32, p<.05$, partial $\eta^{2}=.07$, but smokers and nonsmokers continued to significantly differ, $F(2,92)=15.37, p \leq .01$, partial $\eta^{2}=.15$, after controlling for age. The total N-WAY Supplement Form score was significantly affected by the age of participants, $F(1,92)=$ $5.70, p<.05$, partial $\eta^{2}=.06$, and controlling for age still led to a significant difference when comparing smokers and nonsmokers, $F(2,92)=21.33, p \leq .01$, partial $\eta^{2}=.19$. 
Parallel analyses were conducted to evaluate the effect of age on individual purported nicotine withdrawal symptoms and the impact of each symptom. There were a number of variables where age was found to significantly affect the results. For instance, age played a significant role in the rates of restlessness, nervousness, and conflict with friends, on the NWAY and restlessness and conflict with friends on the N-WAY Supplement Form. With regard to the impact of symptoms, age had a significant effect on: feeling stressed, depression, nervousness, irritability, conflict with friends, and cigarette cravings.

Effect of daily caffeine intake on nicotine withdrawal symptoms. Smokers reported consuming significantly more daily servings of caffeine than nonsmokers, at a near 3:1 margin. Daily caffeine use was significantly correlated with daily smoked cigarettes, $r=.47, p \leq .01$. A one-way ANCOVA was performed, with daily caffeine as a covariate, to better understand caffeine's effect on purported nicotine withdrawal symptoms. Tables 6 and 7 illustrate the findings and effect size, respectively, from the ANCOVA and show that caffeine had a significant effect on the variance of the total N-WAY symptom score, $F(1,92)=15.42, p \leq .01$, partial $\eta^{2}=.15$, impact score, $F(1,92)=8.27, p \leq .01$, partial $\eta^{2}=.08$, and Supplement Form score, $F(1,92)=10.88, p \leq .01$, partial $\eta^{2}=.11$. Nevertheless, smokers had significantly higher total N-WAY symptom, $F(2,92)=11.33, p \leq .01$, partial $\eta^{2}=.11$, impact, $F(2,92)=12.17, p \leq$ .01 , partial $\eta^{2}=.12$, and Supplement Form, $F(2,92)=16.47, p \leq .01$, partial $\eta^{2}=.16$, scores than nonsmokers.

With regard to individual purported nicotine withdrawal symptoms, daily caffeine use was found to have a significant effect on restlessness, anger, headaches, trouble concentrating, dizziness, and conflict with school staff on the N-WAY. On N-WAY Supplement Form responses, daily caffeine consumption had a significant effect on the following potential nicotine 
withdrawal symptoms: restlessness, trouble concentrating, dizziness, conflict with friends, and conflict with school staff. Lastly, the impact of restlessness, anger, trouble concentrating, nervousness, and dizziness, was also significantly affected by daily caffeine use.

Research Question \#1: What Purported Nicotine Withdrawal Symptoms are Reported More Frequently Among Adolescent Smokers than Nonsmokers?

Nicotine withdrawal symptoms and smoking status. A one-way ANCOVA, with age and daily caffeine use as covariates, was performed to evaluate differences in purported nicotine withdrawal symptoms among smokers and nonsmokers. Tables 8 and 9 illustrate the results and effect size, respectively. As measured by the N-WAY, adolescent smokers were found to have higher rates of: anger, feeling depressed, dizziness, conflict with school staff, and cigarette cravings. There were no significant differences in smoker and nonsmoker reports of: restlessness, headaches, trouble concentrating, alertness, feeling tired, feeling stressed, feeling hyper, nervousness, waking up during sleep, irritability, hunger, trouble falling asleep, and conflict with family and friends.

The N-WAY Supplement Form found considerably more differences between smokers and nonsmokers than the N-WAY. A one-way ANCOVA, with age and daily caffeine use as covariates, was conducted and all symptoms occurring at significantly higher rates in smokers than nonsmokers on the N-WAY (feeling angry, feeling depressed, dizziness, conflict with school staff, and cigarette cravings) were also found to differ between smokers and nonsmokers on the N-WAY Supplement Form. In addition, smokers reported significantly higher rates of headaches, nervousness, irritability, and conflict with family than nonsmokers. On the item evaluating alertness, smokers reported significantly lower rates than nonsmokers. 
With regard to the impact of symptoms, smokers demonstrated a higher impact as a result of: alertness, dizziness, irritability, hunger, and cigarette cravings. No significant differences were found in the impact of: restlessness, anger, headaches, trouble concentrating, feeling tired, feeling stressed, feeling hyper, feeling depressed, nervousness, waking up during sleep, trouble falling asleep, and conflict with family and friends between smokers and nonsmokers.

Heavy, light, and nonsmoker differences. A hierarchical regression was performed to evaluate if number of cigarettes smoked a day predicted nicotine dependence and nicotine withdrawal symptoms, controlling for caffeine use. Analyses found that among smoking adolescents, smoking more daily cigarettes was found to predict total N-WAY impact score, $F(1,39)=4.43, p<.05, R^{2}$ change $=.09$, final model $R^{2}=.21$, mFTQ total score, $F(1,39)=$ $11.74, p \leq .01, R^{2}$ change $=.21$, final model $R^{2}=.29$, and mFTQ nicotine dependence classification, $F(1,392)=9.10, p \leq .01, R^{2}$ change $=.19$, final model $R^{2}=.20$. In each case, smoking more daily cigarettes was associated with a higher score. Daily cigarettes smoked, however, was not predictive of total N-WAY symptom, $F(1,42)=.57, p=.45, R^{2}$ change $=.01$, final model $R^{2}=.24$, and Supplement Form, $F(1,42)=1.62, p=.21, R^{2}$ change $=.03$, final model $R^{2}=.19$, scores.

Considering the findings of Prokhorov et al. (2005), where light and nonsmokers did not differ in their rates of certain nicotine withdrawal symptoms, additional analyses were conducted to evaluate any differences between heavy $(\mathrm{n}=32)$, light $(\mathrm{n}=11)$, and nonsmokers. A heavy smoker was defined as smoking more than five cigarettes a day. Tables 10 and 11 illustrate the results and effect size of these analyses, respectively. First, heavy and light smokers were compared. No differences in age or caffeine use were found between the two groups. A one-way ANOVA compared individual nicotine withdrawal symptoms from the N-WAY Supplement 
Form in heavy and light smokers. Only one symptom differed, anger, with light smokers reporting higher rates of symptoms than heavier smokers. No differences in total N-WAY Supplement score were found, $F(1,42)=1.47, p=.23$.

Similar analyses were conducted to compare individual symptoms of light smokers and nonsmokers, with caffeine as a covariate, considering the significant differences in daily intake (no significant age differences were found). Light smokers reported a significantly higher total N-WAY Supplement score, $F(2,60)=31.04, p \leq .01$, partial $\eta^{2}=.23$, and 13 of 19 purported nicotine withdrawal symptoms: restlessness, anger, trouble concentrating, feeling tired, feeling hyper, feeling depressed, nervousness, dizziness, irritability, conflict with family, conflict with friends, conflict with school staff, and cigarette cravings.

When comparing heavy smokers and nonsmokers, controlling for age and daily intake of caffeine, significant differences arose in 6 of 19 symptoms: headaches, feeling alert, nervousness, dizziness, irritability, and cigarette cravings. Alertness was the only symptom heavy smokers reported at a significantly lower rate than nonsmokers. Heavy smokers reported a significantly higher total N-WAY Supplement Form score than nonsmokers, $F(3,82)=6.07, p<$ .05 , partial $\eta^{2}=.07$.

Research Question \#2: Does the N-WAY Act as a Valid Assessment of Adolescent Nicotine Withdrawal Symptoms?

Discrimination between adolescent smokers and nonsmokers. A one-way ANCOVA was conducted to determine differences between adolescent smokers and nonsmokers, as measured by the N-WAY, controlling for age and daily caffeine use. Table 12 illustrates that total N-WAY symptom and impact scores distinguished between smokers and nonsmokers, supporting the initial hypothesis. Smokers reported higher total symptom, $F(3,92)=7.07, p \leq .01$, partial $\eta^{2}=$ 
.07 and impact scores, $F(3,92)=7.49, p \leq .01$, partial $\eta^{2}=.08$, than nonsmokers, outscoring them, on average, 50.27 to 38.46 and 42.01 to 30.38 , respectively. For both measures, however, both age and caffeine use had a significant effect on the variance of the total N-WAY symptom and impact scores. On the N-WAY, there were significant differences among smokers and nonsmokers on 5 of 19 individual symptoms and 6 of 19 impact items, with smokers universally reporting higher rates of symptoms and impact. The N-WAY Supplement Form, in contrast, found differences in 10 of 19 symptoms, with only alertness reported at a significantly lower rate in smokers.

Reliability analyses. The temporal stability of the N-WAY over multiple administrations was evaluated through test-retest reliability. A Pearson-product correlation coefficient was calculated for the two N-WAY administrations, using its total symptom and impact score. Although only 20 of 43 smoking participants completed the second N-WAY administration, results were nonetheless significant. Results indicated similarly strong test-retest correlations for the N-WAY total symptom score, $r=.78, p \leq .01$, and impact score, $r=.74, p \leq .01$.

The internal consistency of the N-WAY was measured through two techniques, split-half reliability, expressed as a Spearman-Brown corrected correlation, and Cronbach's $\alpha$ (Cronbach, 1951). With regard to split-half reliability, items were divided such that the two halves were as equivalent as possible, taking into account order of administration and type of symptom hypothesized to be measured (i.e., physical or emotional). As the two measure different constructs, separate analyses were conducted for N-WAY symptom and impact items. The first half included all odd items and the second half included all even items. Results from the splithalf reliability analysis indicated satisfactory reliability, with symptom and impact correlations 
of $r=.86, p \leq .01$, and $r=.94, p \leq .01$, respectively. Cronbach's $\alpha$ indicated similarly satisfactory internal consistency, with a symptom coefficient of .84 and impact coefficient of .92.

Item analyses were conducted to evaluate each N-WAY item as a functional measurement of nicotine withdrawal symptoms. The analyses calculate each item's corrected item-total correlation and the scale's variance if that item were to be deleted. At first, all 19 symptom and impact items were included in the analysis with its respective total score. All impact items yielded a similar moderate corrected item-total correlation, with all coefficient values exceeding .40. Among symptom items, all items reported corrected item-total correlation greater than .28, except for two items, which had considerably lower correlation coefficients than the other items: "I was alert," $r=-.01$, and "I was hungry," $r=.08$. With all 19 items, the NWAY's total scaled variance was 157.51. Removing "I was alert" and "I was hungry" only decreased scale variance to 153.91 . Refer to Tables 13 and 14 for item analyses results for the NWAY symptom and impact items, respectively.

Concurrent validity of the $N$-WAY to the $m F T Q$. In order to assess the validity of the NWAY, correlations between smokers' total symptom and impact scores with an established measure of nicotine dependence, the mFTQ (Prokhorov et al., 1996), were conducted. Although the two are purported to measure distinct, yet related, constructs, it was hypothesized that a moderate, but significant, relation would exist. Results indicated poor concurrent validity. The total N-WAY symptom, $r=-.09, p=.57$, and impact score, $r=.12, p=.46$, were not significantly correlated with the total mFTQ score. Using the mFTQ categorization of nicotine dependence also yielded not significant correlations with total $\mathrm{N}-\mathrm{WAY}$ symptom, $r=-.18, p=$ .26 , and impact score, $r=-.02, p=.89$. 
Considering the poor concurrent validity of the N-WAY to the mFTQ, additional followup analyses were conducted in order to evaluate the validity of the N-WAY as a measure of adolescent nicotine withdrawal symptoms, but through a different criterion. Bivariate correlations were executed to determine any significant relations between the N-WAY total symptom and impact scores of smokers and two likely correlates of nicotine dependence, number of daily cigarettes smoked (Prokhorov et al., 2005) and number of prior quit attempts (Ulrich, Meyer, Hapke, Rumpf, \& Schumann, 2004). Results indicated that the total N-WAY symptom score significantly correlated with weekly cigarettes smoked, $r=.32, p<.05$, and number of prior quit attempts, $r=.71, p \leq .01$. Similarly, the total N-WAY impact score also significantly correlated with weekly cigarettes smoked, $r=.43, p \leq .01$, and number of prior quit attempts, $r=$ $.70, p \leq .01$.

With these preliminary data, a hierarchical multiple regression analysis was conducted in order to calculate the effect of weekly cigarettes smoked and number of prior quit attempts, while controlling for age and/or daily caffeine use, as necessary. Results indicated that total NWAY impact score was significantly affected by weekly cigarettes smoked, $F(1,39)=5.18, p<$ $.05, R^{2}$ change $=.09$, final model $R^{2}=.36$, and prior quit attempts, $F(1,16)=6.06, p<.05, R^{2}$ change $=.20$, final model $R^{2}=.52$. There was no significant effect of weekly cigarettes smoked, $F(1,39)=.57, p=.45, R^{2}$ change $=.01$, final model $R^{2}=.24$, or number of prior quit attempts, $F(1,16)=1.94, p=.18, R^{2}$ change $=.06$, final model $R^{2}=.51$, on total N-WAY symptom score Measurement of four distinct constructs. An exploratory factor analysis was conducted to determine the dimensionality of the 38 items of the N-WAY among smoking participants. It was hypothesized that four constructs, physical symptoms, physical impact, emotional symptoms, and emotional impact, would arise among smoking participants. According to the 
recommendations of Costello and Osborne (2005), maximum likelihood extraction techniques were utilized. Following extraction, the number of factors retained was determined by the scree test, and one point was retained, as it was the only factor observed to be above the bend in the Eigenvalues graph. An orthogonal rotation method (i.e., Varimax) was used, as it is most likely to produce interpretable results, and a minimum loading criterion of .30 was used for the items, with factors requiring at least three items in order to be considered established (Costello \& Osborne, 2005).

Based upon the plot, one interpretable construct was retained among adolescent smokers, which included all impact and most symptom items. The rotated solution, as seen in Table 10, indicated that 34 of the N-WAY's 38 items accounted for $30.2 \%$ of item-variance. "I was alert," "I was hyper," "I was dizzy," and "I was hungry," were the only items not to load onto this single construct. Thus, the initial hypothesis was not supported as nearly all items were found to be part of a single construct.

\section{Discussion}

The purpose of this study was to evaluate the purported nicotine withdrawal symptoms of current teenage cigarette smokers and to validate a measure of adolescent nicotine withdrawal symptoms. Samples of 13-19 year old smokers and nonsmokers completed questionnaires designed to assess the smoking habits and potential nicotine withdrawal symptoms of smokers and nonsmokers. After controlling for both age and daily caffeine use, there was support for significant differences in 10 of 19 purported nicotine withdrawal symptoms. Smokers, compared to nonsmokers, reported higher rates of: anger, headaches, feeling depressed, nervousness, dizziness, irritability, conflict with family, conflict with school staff, and cigarette cravings and lower rates of alertness. Smokers and nonsmokers did not experience different rates of: 
restlessness, trouble concentrating, feeling tired, feeling stressed, feeling hyper, waking up during sleep, hunger, trouble falling asleep, or conflict with friends. In addition, when comparing heavy, light, and nonsmokers, the data suggest that light smokers may experience more day-today nicotine withdrawal symptoms than heavy smokers.

As a secondary goal of the study, a new measure of adolescent nicotine withdrawal symptoms, the Nicotine Withdrawal Assessment for Youth (N-WAY; Horn, in preparation), was utilized in order to examine its reliability and validity in measuring the construct of nicotine withdrawal symptoms among current adolescent smokers. Total N-WAY symptom and impact scores accurately discriminated between current smokers and nonsmokers. On an individual symptom basis, 5 of 19 symptoms differed between smokers and nonsmokers on the N-WAY. With slight changes in the wording of possible responses aimed to better assess nicotine withdrawal symptoms in current smokers, 10 of 19 potential symptoms significantly differed. The N-WAY was shown to be a reliable and internally consistent assessment. There was poor concurrent validity with the Modified Fagerström Tolerance Questionnaire (mFTQ; Prokhorov et al., 1996), which is an established measure of nicotine dependence. However, one's total NWAY impact score was found to be predicted by two nicotine dependence correlates-number of daily cigarettes smoked (Prokhorov et al., 2005) and prior quit attempts (Ulrich et al., 2004). Sample Characteristics of Smokers and Nonsmokers

Within the sample, adolescent smokers reported smoking about 10 cigarettes a day. Smokers were more likely to reside with a household member who also smokes. This finding is in line with past research indicating that parental smoking behavior increases the likelihood that a child in the home will smoke (Gilman et al., 2009). Similarly, smoking participants were more likely to be exposed to secondhand smoke outside the home. Studies have documented the 
positive relation between secondhand smoke exposures and smoking frequency (Okoli, Browning, Rayens, \& Hahn, 2007). It appears that if teens are in close contact with others who smoke, then they may be more likely to begin and continue to smoke than adolescents not exposed to in-home or out-of-home secondhand smoke.

Similar to previous findings among adolescent smokers (Hollis, Polen, Lichtenstein, \& Whitlock, 2003), about 1 in 4 smokers also reported using either smokeless tobacco or cigars in the past month. There were a number of quantitative differences between reports of purported nicotine withdrawal symptoms among cigarette smokers using these additional tobacco products and only-cigarette smokers. Smokers using smokeless tobacco were found to have lower rates of feeling tired and irritability than only-cigarette smokers. Cigar smokers also reported lower rates of feeling tired than only-cigarette smokers. Perhaps the use of additional nicotine products alleviates certain nicotine withdrawal symptoms. As the half-life of nicotine is about two hours (Benowitz, 1996), using nicotine more frequently, either with cigarettes, smokeless tobacco, or cigars, would increase the body's nicotine concentration, thus preventing certain withdrawal symptoms. There may also be less restriction on the use of smokeless tobacco, compared to cigarettes or cigars, allowing users to consume nicotine when they otherwise may not be able. In a more causal sense, the stimulating effect of nicotine, such as increased heart rate (NIDA, 2006), may counteract feeling tired.

In addition, smokers who use smokeless tobacco were also found to be more dependent on nicotine, according to the mFTQ, and to have more conflict with school staff than onlycigarette smokers. As heavier smokers are more likely to be dependent on nicotine (Kandel et al., 2005), it is understandable that the use of additional nicotine products, such as smokeless tobacco, would also lead to higher rates of nicotine dependence in smokers. Reports of increased 
conflict with school staff among smokeless tobacco users may be a result of the association between nicotine use and delinquent behavior (US DHHS, 1994). In other words, these teens are (possibly illegally) using two tobacco products, and may be more likely to have behavior problems, such as cutting class, getting suspended, and receiving poor grades, than teens that only smoke cigarettes.

With regard to the sample retention, smokers were far more likely to not return the second set of measures than nonsmokers. While this may be a reflection of the general rulebreaking behavior often observed in teenage smokers (NIDA, 1994), another explanation is the method of data collection for smokers and nonsmokers. Initially mailing out the questionnaires yielded a disproportionate amount of nonsmoker respondents. To increase smoker participation, advertisements in area high schools and community centers were directed towards smoking adolescents and they were gathered in person to assure completion of the first set of questionnaires. The second set of questionnaires was mailed to these participants and not returned at a high rate. The change from in-person to mailed administration likely contributed to poor sample retention and reflects the difficulty of recruiting and retaining smoking adolescents in studies and the need for improved methods of data collection.

Participants who dropped out were more likely to smoke more cigarettes, consume more caffeine, and be more impacted by purported nicotine withdrawal symptoms, compared to those remaining in the study. This finding is likely due to the disproportionate amount of smokers who dropped out. In more focused analyses, smokers who dropped out were found to be statistically equal to smokers retained in the study on measures of purported nicotine withdrawal symptoms, only differing on the impact of their hunger. This result demonstrates that there were relatively no differences between retained and dropout smokers, supporting that the findings from the 
second set of questionnaires can be generalized to the smoking sample as a whole. Nonsmoking dropouts reported more household members who smoke, lower rates of feeling tired, and lower rates of impact from trouble concentrating than retained nonsmokers. Similar to the link between smoking and delinquent behavior, perhaps a similar relation exists between having a household member who smokes and rule-breaking behavior, which would affect study retention. Likewise, with more household members smoking, the stimulant effect of nicotine, acquired through secondhand smoke, make counteract fatigue, thus explaining reports of feeling less tired than nonsmokers remaining in the study. Nonsmoking dropouts having less severe trouble concentrating appears to be counterintuitive. One might expect participants with more trouble concentrating to have difficulty completing or remembering to return a second set of questionnaires. Perhaps this finding better reflects these participants being unaware of the impact of their concentration difficulties. Although these participants may indeed have poor concentration, if their insight is low, then they may be unaware of the effect it has on their life. In order to determine if this finding was a statistical anomaly or a true assessment of dropout characteristics in a nonsmoking comparison group, future studies utilizing the N-WAY would benefit from examining this relation.

\section{$N-W A Y$ and $N$-WAY Supplement Form Differences}

The N-WAY was originally designed to be used with adolescents who are in the processes of quitting smoking. It queries any changes in 19 potential nicotine withdrawal symptoms compared to "as usual" over the past week. Thus, the N-WAY does not necessarily measure how often participants experience these symptoms, but if they occur more, less, or the same as usual. During the study's design, it was unclear whether this would produce misleading results. To address this potential confound, the N-WAY Supplement Form was created and 
administered. It included the same potential nicotine withdrawal symptoms, but participants rated how frequently these symptoms occurred over the past week.

Results indicated satisfactory overlap between most items of the N-WAY and the NWAY Supplement Form. Although neither form was designed for nonsmokers, the total scores and all corresponding items were nevertheless significantly correlated among nonsmoking participants. Among smokers, the total scores of each were strongly correlated and the means nearly identical. When pairing the corresponding items of the two measures, 17 of 19 were significantly correlated. The two corresponding items found to be unrelated to one another queried alertness and feeling tired. At a global perspective, there were strong similarities between the two forms, although certain individual items demonstrated only moderate or not significant correlations. These differences confirm that the different wording of the two measurements had an effect on participant responses.

\section{Effect of Age and Daily Caffeine Intake}

Smokers were, on average, about one year older than nonsmokers. This was likely partially due to general population characteristics, where older adolescents are more likely to smoke regularly than younger adolescents (NIDA, 2006). It was also suspected that younger (i.e., under 18 years old) adolescents might have been deterred from participation due to the requirement of parental consent. Some teens reported that they declined participation due to the secrecy of their smoking behavior from their parents. Participants 18 or 19 years old did not require parental consent. Indeed, 18 or 19 year old participants comprised considerably more of the smoking (54\%) than nonsmoking sample (30\%), supporting such a hypothesis.

Smokers also reported consuming significantly more daily servings of caffeine than nonsmokers. There is little information available on adolescent caffeine consumption; surveys 
indicate that children in grades 7-9 consume about one caffeinated beverage a day (Pollak, 2003). There were no available statistics on the caffeine consumption of adolescent smokers. Therefore, it is difficult to assess if the present study's sample consumed more or less caffeine than their cohort. Prior findings, albeit with adult samples, demonstrate a moderately strong relation between caffeine and tobacco use (Istvan \& Matarazzo, 1984). Other studies have found that smokers tend to drink more caffeine on days they smoke more cigarettes (Brown \& Benowitz, 1989), supporting the present study's finding that heavier smokers consumed caffeine at a higher rate. One explanation is that smokers metabolize caffeine at a faster rate than nonsmokers, reducing its half-life (May, Jarboe, VanBakel, \& Williams, 1982). Thus, a smoker would need to consume more caffeine to achieve its desired effects (Benowitz \& Hall, 1989). Another explanation, which has some support, is that caffeine may ameliorate some nicotine withdrawal symptoms. Riedel, Robinson, Klesges, and McLain-Allen (2002) found that adolescent smokers often increase their caffeine intake during a cessation attempt. Swanson, Lee, Hopp, and Berk (1997) further explain that this is often the case because caffeine use appears to have a protective effect against certain nicotine withdrawal symptoms, such as fatigue and headaches. As adolescents likely have more restrictions on when and where they smoke, such as high school bans on smoking (Wakefield et al., 2000), they may use the technique of consuming caffeine to reduce withdrawal symptoms as a form of self-treatment.

Research Question \#1: What Purported Nicotine Withdrawal Symptoms Are Reported More Frequently Among Adolescent Smokers Than Nonsmokers?

The first research question examined what suspected nicotine withdrawal symptoms, and at what impact, smokers experienced more frequently than nonsmokers. Rather than assuming that certain symptoms (e.g., irritability, conflict with family) occurred entirely as a product of 
nicotine withdrawal, it was hypothesized that certain symptoms may occur to some extent in all adolescents, regardless of whether they smoke. Indeed, findings of Prokhorov et al. (2005) demonstrated that there were few differences in many purported nicotine withdrawal symptoms among nonsmokers and light smokers, with nonsmokers reporting significantly more sleep problems. Considering that smokers were, on average, about a year older than nonsmokers and consumed about two more daily caffeinated beverages, analyses controlled for age and caffeine use in determining differences between smokers and nonsmokers. Of the 19 nicotine withdrawal symptoms measured by the N-WAY and completed by current adolescent smokers and nonsmokers, five were reported at a higher rate in smokers: anger, feeling depressed, dizziness, conflict with school staff, and cigarette cravings. Considering the wording of the N-WAY, which queried how often symptoms occurred compared to "as usual", the N-WAY Supplement Form was administered with wording designed to better assess symptom frequency. In addition to the five symptoms elevated on the N-WAY, the N-WAY Supplement Form found differences on six additional symptoms: alertness, restlessness, headaches, nervousness, irritability, and conflict with family, with smokers reporting higher rates on all but alertness. The following rates of 8 of 19 symptoms did not differ among smokers and nonsmokers: trouble concentrating, feeling tired, feeling stressed, feeling hyper, waking up during sleep, hunger, trouble falling asleep, and conflict with friends. Smokers were found to be impacted more as a result of six symptoms: alertness, dizziness, irritability, hunger, conflict with school staff, and cigarette cravings.

With the support of the N-WAY and/or N-WAY Supplement Form, there was evidence that most (10 of 19) of the purported nicotine withdrawal symptoms differed among teen smokers and nonsmokers, with only alertness occurring less frequently in smokers. Of the remaining symptoms, there was some support from prior studies for the lack of differences in 
rates of trouble concentrating, hunger, waking up during sleep, and trouble falling asleep. Prokhorov et al. (2005) also found that rates of trouble concentrating and hunger did not differ among nonsmokers and light smokers, and nonsmokers reported significantly more sleep problems than nonsmokers. It may be that the current study contained a sufficient amount of light smokers to dilute any differences that would have been found between heavy and nonsmoking participants. If, as the present study's results suggest, smokers and nonsmokers are indeed experiencing relatively equal rates of sleep problems (such as waking up during sleep and trouble falling asleep), it is reasonable to suggest that the two populations may also feel tired at the same rate, which findings also indicated.

Daily caffeine intake was found to have a significant effect on 6 of 19 nicotine withdrawal symptoms: restlessness, anger, headaches, dizziness, conflict with friends, and conflict with school staff. In each case, more daily caffeine consumption was predictive of higher rates of nicotine withdrawal symptoms. As heavier smokers were also more likely to consume larger amounts of daily caffeine, this finding supports the earlier argument of caffeine being used to alleviate some adolescent nicotine withdrawal symptoms. As a readily available and legal substance, caffeinated beverages are often used by adolescents as an aid during quit attempts (Riedel et al., 2002) and have been shown to reduce some nicotine withdrawal symptoms (Swanson et al., 1997). Perhaps current smokers utilize caffeine in a similar manner, particularly when their smoking behavior is restricted.

An alternate explanation is that day-to-day caffeine withdrawal symptoms may be somewhat responsible for the report of certain purported nicotine withdrawal symptoms that also mirror caffeine withdrawal symptoms, such as headaches, irritability, or poor concentration (Juliano \& Griffiths, 2004). The adolescent nicotine withdrawal symptom literature has never 
controlled for age or caffeine use. By covarying the effect of caffeine intake, perhaps a clearer depiction of smoker/nonsmoker differences is illustrated. In other words, these results suggest that current smokers and nonsmokers may be more similar to one another in their experience of a number of purported nicotine withdrawal symptoms. Other variables, such as caffeine use, may best account for differences in the rates of certain symptoms.

Considering that smoking participants were current smokers not engaged in a cessation attempt, the nicotine withdrawal symptoms experienced (if at all) were likely not as frequent or severe as observed in smokers attempting to quit. Nicotine's half life is about two hours (Benowitz, 1996) and the first nicotine withdrawal symptoms have been observed in as little as 30 minutes after smoking; thus, it is likely that some nicotine withdrawal symptoms were experienced among smoking participants. However, variables such as time between cigarettes, daily cigarettes smoked, severity of nicotine dependence, and daily caffeine intake all play a role in the rates and impact of nicotine withdrawal symptoms. Despite these potential barriers, most purported nicotine withdrawal symptoms were found to occur at different rates in smokers and nonsmokers, suggesting that current smokers indeed experienced nicotine withdrawal symptoms, even in the absence of a cessation attempt. Results demonstrating no significant differences in nine purported nicotine withdrawal symptoms (restlessness, trouble concentrating, feeling tired, feeling stressed, feeling hyper, waking up during sleep, hunger, trouble falling asleep, and conflict with friends) may represent that it is normative for all adolescents to experience these symptoms and smoking does not intensify them. The absence of differences may also demonstrate that these withdrawal symptoms occur later in the smoking cessation process, beyond what current smokers would experience when smoking freely. In order to further 
evaluate these nicotine withdrawal symptoms, future studies are needed with participants in the process of smoking cessation along with a nonsmoking comparison group.

Heavy, light, and nonsmoker differences. Considering the results of Prokhorov et al. (2005), it would be expected that light and nonsmokers would have more similar rates of nicotine withdrawal symptoms than heavier and nonsmokers. However, the opposite was found to occur. While light and heavy smokers had statistically equal rates of 18 of 19 purported nicotine withdrawal symptoms, light smokers significantly differed from nonsmokers on more (13 of 19) purported nicotine withdrawal symptoms than did heavier smokers (6 of 19). In other words, results suggest that light daily smokers may experience more day-to-day nicotine withdrawal symptoms than heavier smokers.

Although previous findings have documented that heavier smokers experience withdrawal symptoms quicker after their last cigarette (DiFranza \& Ursprung, 2008) and have higher rates of nicotine withdrawal symptoms than lighter smokers (Ershler et al., 1989; McNeill et al., 1986; Prokhorov et al., 2005), these data were collected from smokers during smoking cessation. In contrast, the present study utilized current smokers. Heavy smokers, despite having a faster latency to withdrawal (DiFranza \& Ursprung, 2008), may better prevent and alleviate nicotine withdrawal symptoms as a function of smoking frequently. As the half life of nicotine is two hours (Benowitz, 1996), heavy smokers could smoke sufficiently to keep nicotine levels high enough such that minimal nicotine withdrawal symptoms occur. Perhaps lighter smokers, who are also dependent on nicotine at high rates (DiFranza et al., 2002b), do not smoke frequently enough to outpace the metabolization of nicotine. Furthermore, daily caffeine consumption was positively correlated to daily cigarettes smoked. If caffeine does indeed reduce certain nicotine withdrawal symptoms (Swanson et al., 1997), it can be argued that its frequent 
use likely contributed to lower than expected reports of nicotine withdrawal symptoms from current heavy smokers. As these results demonstrate, light smokers may experience more day-today nicotine withdrawal symptoms than their heavier smoking counterparts, on account of their body's nicotine concentration and caffeine intake throughout the day.

Research Question \#2: Does the N-WAY Act as a Valid Assessment of Adolescent Nicotine Withdrawal Symptoms?

As a newly created measure of adolescent nicotine withdrawal symptoms, the N-WAY (Horn, in preparation) was evaluated to determine its reliability and validity. As reviewed in Noar (2003), in order to validate a measure, face and content validity must first be established. Then, the construct validity of a measure, or in the current study's case, the extent that the NWAY accurately measures adolescent nicotine withdrawal symptoms, is to be evaluated. Through the involvement of 10 experts in the field during test construction, face and content validity has been assumed to be established. Construct validity was measured though four procedures: 1) discrimination between current smokers and nonsmokers; 2) reliability analyses, which include temporal stability, internal consistency, and item analyses; 3) concurrent validity with a previously established measure, the mFTQ (Prokhorov et al., 2000), and 4) the measurement of the four hypothesized constructs (physical and emotional symptoms and physical and emotional impact).

Discrimination between adolescent smokers and nonsmokers. Generally speaking, total N-WAY symptom and impact scores accurately distinguished current smokers from nonsmokers. Smokers significantly outscored nonsmokers on total symptom and impact score. The N-WAY indicated, as hypothesized, that smokers reported nicotine withdrawal symptoms occurring more frequently and at a higher impact. This finding supports that N-WAY is measuring some 
construct, assumed to be nicotine withdrawal symptoms, which occurs at different rates in smokers and nonsmokers.

On a more detailed level, only 5 of 19 purported nicotine withdrawal symptoms were found at higher rates in smokers. The symptoms that the N-WAY discriminated between smokers and nonsmokers were: anger, feeling depressed, dizziness, conflict with school staff, and cigarette cravings, all with smokers reporting higher rates. Although there were no significant differences between smokers and nonsmokers on the remaining 14 symptoms, smokers did report higher rates on each than nonsmokers. This finding suggests that perhaps with a larger sample, some of these symptoms would significantly differ between smokers and nonsmokers. As discussed earlier, the N-WAY Supplement Form found additional differences, which implies that the wording of the N-WAY (comparing current functioning to "as usual"), combined with the study's sample of current smokers, may have masked some specific item differences between smokers and nonsmokers. Generally speaking, the N-WAY is judged to satisfactorily distinguish between smokers and nonsmokers when its total symptom and impact scores are used. On an individual-item level, it is less successful at discriminating between current adolescent smokers and nonsmokers with its current wording.

Reliability analyses. In order to determine if the N-WAY is a consistent measure, various statistical analyses were performed on the smoking sample's responses. Test-retest reliability analysis was conducted and determined a strong correlation for the N-WAY total symptom and impact score over the two administrations, separated by one week. These scores are comparable to the test-retest reliability of the mFTQ at 2-month (Prokhorov et al., 1998) and 6-month intervals (Wellman et al., 2006). As less than half of smoking participants completed the second administration of the N-WAY, the test-retest reliability results may not necessarily be 
representative of a larger sample. Two related results, however, support that the findings can be generalized to a larger sample. Firstly, smokers who dropped out and those completing the study were virtually homogenous (the two samples only differed on the impact of hunger). Second, the test-retest reliability of nonsmokers was nearly identical for both total symptom and impact score. Although this is not the population of interest, there were far more participants who completed both sets of N-WAY administration than smokers. This further demonstrates that the N-WAY is a measure that yields consistent scores over a short period of time (e.g., one week).

In the split-half reliability measurements, the N-WAY was divided into two halves, each being as equivalent as possible to the other, to examine its consistency. In other words, this measurement determines if two supposedly equal halves of a test are indeed equal. The strong correlations between the symptom and impact halves indicate that each measured a single construct, assumed to be nicotine withdrawal symptoms. Although split-half reliability does not measure validity, these results nevertheless support the study's hypothesis that the N-WAY has strong psychometric properties. As a measure of internal consistency, or how well the N-WAY reliably measures a single construct, Cronbach's $\alpha$ (Cronbach, 1951) was calculated for smoker responses on the N-WAY. In addition to strong symptom and impact internal consistency, the findings were similar and superior to the internal consistency of the mFTQ (Prokhorov et al., 2000; Wellman et al., 2006), respectively. These figures demonstrate that these N-WAY scores approached or exceeded commonly used standards of internal consistency for assessments of health-related behavior (Cronbach's $\alpha \geq .85$; McDowell \& Newell, 1996). Taken together, these results confirm that the N-WAY consistently and reliably measures a single construct.

From correlations with total N-WAY score and change in variance if removed, item analyses demonstrated the utility of each N-WAY item. All N-WAY impact items, for instance, 
were found to be useful predictors of total N-WAY impact score and the removal of any item would be deleterious to the measure as a whole. This finding indicates that all impact items are meaningful and, in future versions of the N-WAY, should be retained. N-WAY symptom items, on the other hand, were not as universally functional, according to these analyses. Two items, "I was alert" and "I was hungry" did not significantly correlate with the total N-WAY symptom score. In addition, the removal of items measuring alertness and hunger did not lead to any considerable changes in total scale variance. There was no evidence that measuring hunger was useful, on the item analyses or otherwise, in the measurement of nicotine withdrawal symptoms. Rates of hunger did not differ between smokers and nonsmokers and it was not included as part of the single factor of the exploratory factor analysis. Alertness, in contrast, was found to significantly differ between smokers and nonsmokers on the N-WAY Supplement Form. It was also the only item found to occur at significantly lower rates in smokers than nonsmokers. Considering this finding, this item may be qualitatively different than other variables. This result may explain its exclusion as a meaningful variable on the item analyses and factor analysis. Considering that the impact of this symptom was higher in smokers than nonsmokers, there is some evidence of its utility for use in adolescent smoker populations. Generally speaking, these results imply that, within the population of current smokers, it may not be necessary to inquire about hunger and future versions of the N-WAY should consider removing this item when assessing current smokers.

Concurrent validity with the $m F T Q$. With data indicating that the N-WAY is a reliable and consistent measure, the following step is to determine if the N-WAY validly measures the construct of nicotine withdrawal symptoms. The N-WAY total symptom and impact scores were not significantly correlated to the mFTQ total score, an indication of nicotine dependence. These 
figures are considerably lower than expected. As a basis for comparison, the concurrent validity of the mFTQ and the Hooked on Nicotine Checklist (DiFranza et al., 2002a), which both purport to measure nicotine dependence, was far stronger, with total score correlations of .83 (Wellman et al., 2006). This finding may be best explained by the different constructs that the N-WAY and mFTQ aim to measure. As theorized, nicotine withdrawal and dependence symptoms are different and demonstrate a need to be measured in different ways. Although withdrawal symptoms are one of many nicotine dependence symptoms, many nicotine dependence measures, such as the mFTQ, do not ask explicit questions about withdrawal symptoms, instead focusing more on smoking frequency and habits. This further demonstrates the need for an assessment of adolescent nicotine withdrawal symptoms that is separate from previous measures of nicotine dependence symptoms, as the two are distinct constructs. Rather than a weakness of the N-WAY, this may be evidence that the N-WAY does measure nicotine withdrawal symptoms, which does not overlap with nicotine dependence symptoms. In order to evaluate the concurrent validity of the N-WAY, alternate measures of nicotine withdrawal symptoms were utilized for follow-up analyses. Prior studies have indicated that number of cigarettes smoked (Prokhorov et al., 2005) and prior quit attempts (Ulrich et al., 2004) were positively correlated with nicotine withdrawal symptoms in prior studies. Therefore, these variables may be applicable frames of reference to measure the concurrent validity of the N-WAY.

Follow-up hierarchical regressions were conducted in order to measure any relation between the total N-WAY symptom and impact scores and other variables that would be expected to be associated with nicotine withdrawal symptoms, while controlling for age and daily caffeine intake. When using number of cigarettes smoked and prior quit attempts as alternate indicators of nicotine withdrawal symptoms, a smoker's total N-WAY impact score 
was found to be predicted by daily cigarette use and number of prior quit attempts. The results suggest that the total N-WAY impact score may potentially be a useful measure of nicotine withdrawal symptoms among current smokers.

Results suggesting that heavy smokers experience less day-to-day nicotine withdrawal symptoms than light smokers may also explain the poor correlation between the N-WAY and mFTQ. The number of daily cigarettes smoked was associated with higher levels of nicotine dependence; however, heavy smokers were shown to be more similar to nonsmokers than were light smokers on measures of nicotine withdrawal symptoms. Thus, the smokers most likely to have high mFTQ scores may have reported lower levels of nicotine withdrawal symptoms. As discussed above, smoking cigarettes heavily may ward off nicotine withdrawal symptoms and simultaneously strengthen dependence on nicotine. Lighter smokers may be less dependent, but do not smoke enough to sufficiently prevent day-to-day nicotine withdrawal symptoms.

The validity of the N-WAY is promising, although unclear based upon these conflicting results. On the one hand, the N-WAY did not correspond to the mFTQ, an established measure of adolescent nicotine dependence. On the other hand, nicotine withdrawal and dependence symptoms may be distinct constructs that would not be expected to overlap. Furthermore, number of weekly cigarettes smoked and prior quit attempts (two correlates of nicotine withdrawal symptoms) significantly predicted total N-WAY impact score, indicating an association between the variables. In addition, the data suggest that smokers likely to be most nicotine dependent may have reported lower nicotine withdrawal symptoms and vice-versa. The findings supporting the validity of the N-WAY as a measure of adolescent nicotine withdrawal symptoms are strengthened by the previous demonstration of strong reliability and internal consistency figures. While these results are promising and do somewhat support the validity of 
the N-WAY, additional studies must be conducted in order to assertively deduce that the NWAY validly measures the construct of adolescent nicotine withdrawal symptoms.

Measurement of four distinct constructs. An exploratory factor analysis was conducted in order to determine if, as hypothesized, the N-WAY would consist of four constructs. During its assembly, the N-WAY was thought to measure: physical symptoms, physical impact, emotional symptoms, and emotional impact. Generally, the data did not support the study's initial hypothesis of four measured dimensions of the N-WAY. Rather, it appears that most of the NWAY items measure the same construct, assumedly nicotine withdrawal symptoms, and results do not distinguish between physical and emotional symptoms or their impact. Although this result contradicts initial predictions, it does not necessarily imply poor N-WAY validity. The mFTQ, for instance, also contains only one dimension (Wellman et al., 2006). Results suggest that future use of the N-WAY among current smokers should not distinguish between the four previously hypothesized constructs. Rather, all items should be considered to measure a single construct.

\section{Study Limitations and Future Directions}

The most glaring limitation of the present study is the use of current smokers rather than smokers in the process of cessation. Data suggest that smokers' ongoing use of nicotine alleviated or prevented certain withdrawal symptoms, particularly among heavier smokers. If a smoker habitually smokes in order to avoid experiencing aversive nicotine withdrawal symptoms, then those symptoms, in theory, are not occurring and would not be reported as such. As hypothesized and demonstrated by the results, however, smokers appeared to experience certain nicotine withdrawal symptoms, despite continuing to smoke. It is likely that greater differences between smokers and nonsmokers, with regard to the frequency and impact of 
symptoms, would likely be found with a sample of smokers engaging in a quit attempt. Further examination of differences in withdrawal symptoms could occur with three comparison groups: nonsmokers, smokers, and smokers attempting to quit. This would also allow for the study of the reliability and validity of the N-WAY among three unique samples.

The use of current, as opposed to quitting, smokers may not have been an ideal sample to examine the psychometric properties of the N-WAY. Considering that the N-WAY assessed how often symptoms occurred compared to "as usual," the N-WAY, with its current wording, may be best suited to examine changes in withdrawal symptoms rather than the stable experience of withdrawal by current smokers. As the differences between the N-WAY and N-WAY Supplement Form suggest, the wording of the possible responses likely led to differences in participant responses. In the absence of a sample of adolescents quitting smoking, future studies should consider using the wording of the N-WAY Supplement Form in place of the N-WAY symptom items. Additionally, in order to determine the reliability and validity of the N-WAY as a measure of nicotine withdrawal symptoms among smokers during a cessation attempt, future samples of that population are needed. For instance, despite no support for the use of "I was hungry" as an essential N-WAY item among current smokers, its utility may grow in a sample of teen smokers in the process of quitting.

As participants predominantly resided in West Virginia, the present study's cultural diversity mirrored that of the state. Nevertheless, a number of cultures were underrepresented. To allow for a better understanding of smoking habits and nicotine withdrawal symptoms, particularly among non-Caucasian adolescents, a more diverse sample is needed. Additionally, a larger sample would also increase the power and potentially uncover more subtle findings than with the current study's sample size of 93. Considering that smokers were, on average, in their 
late teens, future studies should also more heavily recruit younger smokers to evaluate their nicotine withdrawal symptoms. Such a step may also avoid the present study's one-year average age difference between smokers and nonsmokers. Similarly, smokers were found to consume about two more daily caffeinated beverages than nonsmokers. Although this may be characteristic of smokers, taking steps to assure homogenous samples of smokers and nonsmokers, such as with matching techniques, will likely lead to more straightforward conclusions. In the absence of similar smoking and nonsmoking samples, it is strongly recommended that future studies evaluate and, if necessary, control for age, daily caffeine consumptions, and other confounding variables as part of their statistical analyses.

The finding that smokers, on average, consumed about two more daily servings of caffeine is one that raises some important issues. The tobacco-caffeine link has not been a relation studied much in the adolescent literature. Nevertheless, the present study's results suggest that caffeine use may play a large role in smokers' experience of purported nicotine withdrawal symptoms. The present study, however, was limited by its lack of specificity in assessing caffeine consumption. Participants were queried on how many servings of caffeinated beverages they consumed, with no differentiation between drinks with high (e.g., energy drinks) and low (e.g., tea) caffeine content. Thus, the participants' true caffeine intake can only be estimated from the amount of self-reported servings consumed. Future studies would be wise to assess what and how many of specific caffeinated beverages or other sources of caffeine adolescents are consuming, in order to more accurately calculate caffeine intake.

Particularly when considering the poor retention of smoking participants-over half of the sample dropped out — an increased sample size would have improved the power of conclusions drawn with regard to stability over time. As discussed, mailing the second set of 
questionnaires, as opposed to collecting data in person, likely contributed to the low response rate in smokers. Improving participant compensation, which may include increasing payment or employing a more desirable incentive, is likely to facilitate participant retention. Even a small gesture, such as restructuring when gift cards are provided, may lead to a positive change. The current study provided a $\$ 10$ gift card after the completion of each set of questionnaires, which may not have acted as sufficient encouragement to continue participation over time. Generally speaking, future studies can improve upon the present study with increased cultural diversity, sample size, and retention rates.

While the use of mailed questionnaires to collect data may have expanded the range of possible participants, a drawback of this method is the loss of regulation over when the questionnaires are completed. Participants were mailed a second set of questionnaires one week after the completion of the first set. However, there was no accurate way to oversee when the questionnaires were truly completed. Additionally, some participants completed their first set of questionnaires in person and others through the mail. Administering the questionnaires in a more standardized manner is recommended for future studies in order to avoid these possible confounds.

The absence of documented concurrent validity with an established measure of nicotine dependence precludes firm conclusions concerning the validity of the N-WAY. It is of interest to see if similar results would be found through the use of other adolescent measures of nicotine dependence, such as the Hooked on Nicotine Checklist (DiFranza et al., 2002a), or a checklist of DSM-IV (American Psychiatric Association, 2000) nicotine withdrawal symptoms. Additionally, the use of more objective, albeit more complex, markers of nicotine exposure, such as cotinine analysis, may provide more specific data regarding nicotine intake than a self-report. This would 
lead to clearer information about the relation between nicotine in the body and the experience of withdrawal symptoms. Furthermore, establishing the test-retest reliability of the N-WAY over longer periods of time is another area that future studies can address. While the present study indicated satisfactory test-retest reliability over the course of a week, conclusions cannot be drawn regarding longer time intervals.

As an assessment tool, the value of the N-WAY lies in its ability to accurately evaluate nicotine withdrawal symptoms and their impact on adolescents. Further study of the N-WAY could lead to a criterion for classifying the severity of one's nicotine withdrawal symptoms. In other words, with improved understanding of the meaning of one's N-WAY score, researchers could specify the range of mild, moderate, and severe nicotine withdrawal symptoms. Additionally, by linking one's N-WAY score to a practical treatment outcome, future studies can expand upon its utility. For instance, studying if higher N-WAY scores indicate that a smoker will have more difficulty quitting or whether the report of certain symptoms indicates the need for certain smoking cessation services would be useful information for treatment providers utilizing the N-WAY.

\section{Conclusions}

The present study suggests that current smokers and nonsmokers experience significantly different rates of nicotine withdrawal symptoms. After controlling for age and daily caffeine intake, 10 of 19 measured symptoms were found to differ among smokers and nonsmokers, 9 of which occurred at higher rates in current smokers. Furthermore, the impact as a result of 5 of 19 symptoms differed between smokers and nonsmokers, with smokers reporting more life disruption. Nevertheless, there were a number of purported nicotine withdrawal symptoms, such as sleep problems, trouble concentrating, feeling stressed, feeling hyper, hunger, and conflict 
with friends, which did not differ among current smokers and nonsmokers. In the absence of an ongoing smoking cessation attempt, perhaps the full effect of nicotine withdrawal symptoms did not transpire.

Sample smokers were found to be older and consume more daily servings of caffeine than nonsmokers. Particularly the link between caffeine and nicotine withdrawal symptoms bears to be explored further. Perhaps caffeine can be used to ameliorate certain nicotine withdrawal symptoms and teens use this strategy given the legality of caffeine and restrictions on their smoking behavior. It is also possible that day-to-day caffeine withdrawal symptoms, such as headaches, irritability, poor concentration, and decreased alertness (Juliano \& Griffiths, 2004), may be mistaken for day-to-day nicotine withdrawal symptoms. Another compelling and unexpected finding is that heavier smokers experience the same, or potentially less, day-to-day nicotine withdrawal symptoms than light smokers. It may be that more frequent nicotine use effectively prevents and eases withdrawal symptoms. This may further explain the transition from light to heavy smoking; smoking more frequently is technically an effective method of alleviating certain day-to-day nicotine withdrawal symptoms among current smokers.

The Nicotine Withdrawal Assessment for Youth (N-WAY; Horn, in preparation) was found to be a reliable and internally consistent measure. Its total score was found to accurately distinguish between smokers and nonsmokers and there is some evidence that its total impact score may accurately measure nicotine withdrawal symptoms. On the other hand, it had poor concurrent validity with a measure of nicotine dependence symptoms, although this may reflect the differences in the constructs of nicotine withdrawal and dependence symptoms. In addition, shifting the wording of possible responses, comparing the occurrence of symptoms to "as usual," appeared to lead to significant differences between smokers and nonsmokers in 10 of 19 
individual N-WAY items. Based on these findings, utilizing the wording of the N-WAY Supplement Form to measure the frequency of symptoms is recommended among populations of current smokers. Additionally, there were no indications that items measuring hunger meaningfully contributed to the assessment of the N-WAY and its removal on future versions of the N-WAY to be used with current smokers is suggested. Lastly, there was no evidence that multiple constructs were measured (e.g., physical and emotional symptoms). Rather, one construct, assumed to be related to nicotine withdrawal symptoms, included most (15 of 19) NWAY items, suggesting that physical and emotional symptoms measure a single concept in a similar fashion.

While results measuring the reliability and internal consistency of the N-WAY are promising, further study is needed to evaluate the validity of N-WAY as an assessment of adolescent nicotine withdrawal symptoms. Although differences were elucidated between current smokers and nonsmokers, there were a number of withdrawal symptoms that were similar, particularly after controlling for age and daily caffeine use. Perhaps this indicates that all adolescents— whether they smoke or not—experience certain purported nicotine withdrawal symptoms at the same rate and age and daily caffeine consumption best explains their occurrence. The ability to better identify withdrawal symptoms in adolescent smokers that are truly due to nicotine use is a critical step in treatment planning. As prior studies demonstrate, withdrawal symptoms are a primary reason for a smoking cessation failure, which occurs $88 \%$ of the time (Sussman, 2002). With an improved understanding of adolescent nicotine withdrawal symptoms and a method for assessing it, treatment providers will have an additional tool to improve rates of adolescent smoking cessation success. 


\section{References}

American Psychiatric Association (2000). Diagnostic and statistical manual of mental disorders ( $4^{\text {th }}$ ed., text rev.). Washington, DC: American Psychiatric Association.

Benowitz, N. L. (1996). Pharmacology of nicotine: Addiction and therapeutics. Annual Review of Pharmacological Toxicology, 36, 597-613.

Benowitz, N. L., \& Hall, S. M. (1989). Persistent increase in caffeine concentrations in people who stop smoking. British Medical Journal, 298, 1075-1076,

Brown, C. R., \& Benowitz, N. L. (1989). Caffeine and cigarette smoking: Behavioral, cardiovascular, and metabolic interactions. Pharmacology, Biochemistry, and Behavior, $34,565-570$.

Burns, D. M., \& Johnston, L. D. (2001). Overview of recent changes in adolescent smoking. In NIH Publication No. 02-5086: Smoking and Tobacco Control Monograph No. 14.

Bethesda, MD: U.S. Department of Health and Human Services, Public Health Service, National Institutes of Health, National Cancer Institute.

Centers for Disease Control and Prevention (1994). Reasons for tobacco use and symptoms of nicotine withdrawal among adolescent and young adult tobacco users_-United States, 1993. Morbidity and Mortality Weekly Report, 43, 745-750.

Centers for Disease Control and Prevention (2008). Cigarette smoking among adults_-United States, 2007. Morbidity and Mortality Weekly Report, 57, 1221-1226.

Cronbach, L. J. (1951). Coefficient alpha and the internal structure of tests. Psychometrika, 16, 297-334. 
Colby, S. M., Tiffany, S. T., Shiffman, S., \& Niaura, R. S. (2000). Are adolescent smokers dependent on nicotine? A review of the evidence. Drug and Alcohol Dependence, 59, 8395.

Collins, L. M., \& Graham, J. W. (2002). The effect of the timing and spacing of observations in longitudinal studies of tobacco and other drug use: Temporal design considerations. Drug and Alcohol Dependence, 68, S85-S96.

Costello, A. B., \& Osborne, J. W. (2005). Best practices in exploratory factor analysis: Four recommendations for getting the most from your analysis. Practical Assessment Research \& Evaluation, 10. Available online at http://pareonline.net/getvn.asp?v=10\&n=7.

DiFranza, J. R., Rigotti, N. A., McNeill, A. D., Ockene, J. K., Savageau, J. A., St. Cyr, D., et al. (2000). Initial symptoms of nicotine dependence in adolescence. Tobacco Control, 9 , 313-319.

DiFranza, J. R., Savageau, J. A., Fletcher, K., Ockene, J. K., Rigotti, N. A., McNeill, A. D., et al. (2002a). Measuring the loss of autonomy over nicotine use in adolescents: The DANDY (development and assessment of nicotine dependence in youths) study. Archives of Pediatric and Adolescent Medicine, 156, 397-403.

DiFranza, J. R., Savageau, J. A., Rigotti, N. A., Fletcher, K., Ockene, J. K., McNeill, A. D., et al. (2002b). Development of symptoms of tobacco dependence in youths: 30 month follow up data from the DANDY study. Tobacco Control, 11, 228-235.

DiFranza, J. R., \& Ursprung, W. W. S. A. (2008). The latency to the onset of nicotine withdrawal: A test of the sensitization-homeostasis theory. Addictive Behaviors, 33, 1148-1153. 
Dino, G., Kamal, K., Horn, K., Kalsekar, I., \& Fernandes, A. (2004). Stage of change and smoking cessation outcomes among adolescents. Addictive Behaviors, 29, 935-940.

Duncan T. E., Duncan, S. C., \& Strycker, L. A. (2006). An introduction to latent variable growth curve modeling: Concepts, issues, and applications ( $2^{\text {nd }}$ ed.). Mahwah, NJ: Lawrence Eribaum Associates, Inc.

Ershler, J., Leventhal, H., Fleming, R., \& Glynn, K. (1989). The quitting experience for smokers in sixth through twelfth grades. Addictive Behaviors, 14, 365-378.

Fagerström, K. O. (1978). Measuring degree of physical dependency to tobacco smoking with reference to individualization of treatment. Addictive Behaviors, 3, 235-241.

Gilman, S. E., Rende, R., Boergers, J., Abrams, D. B., Buka, S. L., Clark, M. A., et al. (2009). Parental smoking and adolescent smoking initiation: An intergenerational perspective on tobacco control. Pediatrics, 123, 274-281.

Grimshaw, G. M., \& Stanton, A. (2006). Tobacco cessation interventions for young people. Cochrane Database of Systematic Reviews, 4, Article No: CD003289.

Grimshaw, G., Stanton, A., Blackburn, C., Andrews, K., Grimshaw, C., Vinogradova, Y., et al. (2003). Patterns of smoking, quit attempts and services for a cohort of 15- to 19-year olds. Child: Care, Health and Development, 29, 457-464.

Heatherton, T. F., Kozlowski, L. T., Frecker, R. C., \& Fagerström, K. O. (1991). The Fagerström Test for Nicotine Dependence: A revision of the Fagerström Tolerance Questionnaire. British Journal of Addictions, 86, 1119-1127.

Hendricks, P. S., Ditre, J. W., Drobes, D. J., \& Brandon, T. H. (2006). The early time course of smoking withdrawal effects. Psychopharmacology, 187, 385-396.

Henningfield, J. E. (1995). Nicotine medications for smoking cessation. New England Journal of 
Medicine, 333, 1196-1203.

Hollis, J. F., Polen, M. R., Lichtenstein, E., \& Whitlock, E. P. (2003). Tobacco use patterns and attitudes among teens being seen for routine primary care. American Journal of Health Promotion, 17, 231-239.

Horn, K. A. (in preparation). The nicotine withdrawal assessment for youth. Manuscript in preparation.

Horn, K., Dino, G., Kalsekar, I., \& Mody, R. (2005). The impact of not on tobacco on teen smoking cessation: End-of program evaluation results, 1998 to 2003. Journal of Adolescent Research, 20, 640-661.

Horn, K., Fernandes, A., Dino, G., Massey, C. J., \& Kalsekar, I. (2003). Adolescent nicotine dependence and smoking cessation outcomes. Addictive Behaviors, 28, 769-776.

Horn, K., McGloin, T., Dino, G., Manzo, K., Lowry-Chavis, L., Shorty, L., et al. (2005). Quit and reduction rates for a pilot study of the american indian not on tobacco (N-O-T) program. Preventing Chronic Disease, 2, 13.

Istvan, J., \& Matarazzo, J. D. (1984). Tobacco, alcohol, and caffeine use: A review of their interrelationships. Psychological Bulletin, 95, 301-326.

Johnston, L. D., O'Malley, P. M., Bachman, J. G., \& Schulenberg, J. E. (2005). Monitoring the Future national results on adolescent drug use: Overview of key findings, 2004. NIH Publication No. 05-5726. Bethesda, MD: National Institute on Drug Abuse

Juliano, L. M., \& Griffiths, R. R. (2004). A critical review of caffeine withdrawal: Empirical validation of symptoms and signs, incidence, severity, and associated features. Psychopharmacology, 176, 1-26. 
Kandel, D., Schaffran, C., Griesler, P., Samuolis, J., Davies, M., \& Galanti, R. (2005). On the measurement of nicotine dependence in adolescence: Comparisons of the $\mathrm{mFTQ}$ and a DSM-IV-based scale. Journal of Pediatric Psychology, 30, 319-332.

Kassel, J. D. (2000). Are adolescent smokers addicted to nicotine? The suitability of the nicotine dependence construct as applied to adolescents. Journal of Child and Adolescent Substance Use, 9, 77-91.

Killen, J. D., Ammerman, S., Rojas, N., Varady, J., Haydel, F., \& Robinson, T. N. (2001). Do adolescent smokers experience withdrawal effects when deprived of nicotine? Experimental and Clinical Psychopharmacology, 9, 176-182.

King, G., Honaker, J., Joseph, A., \& Scheve, K. (1998, September). Listwise deletion is evil: What to do about missing data in political science. Paper presented at the Annual Meeting of the American Political Science Association, Boston, MA.

Lancaster, T., Stead, L., Silagy, C. \& Sowden, A. (2000). Effectiveness of interventions to help people stop smoking: Findings from the cochrane library. British Medical Journal, 321, 355-358.

Lawshe, C. H. (1975). A quantitative approach to content validity. Personnel Psychology, 28, 563-575.

May, D. C., Jarboe, C. H., VanBakel, A. B., \& Williams, W. M. (1982). Effects of cimetidine on caffeine disposition in smokers and nonsmokers. Clinical Pharmacology and Therapeutics, 31, 656-661.

McDowell, I., \& Newell, C. (1996). Measuring health: A guide to rating scales and questionnaires. New York: Oxford University Press. 
McGee, R., \& Stanton, W. R. (1993). A longitudinal study of reasons for smoking in adolescence. Addiction, 88, 265-271.

McGinnis, J. M., \& Foege, W. H. (1993). Actual causes of death in the United States. The Journal of the American Medical Association, 270, 2201-2212.

McNeill, A. D., West, R. J., Jarvis, M., Jackson, P., \& Bryant, A. (1986). Cigarette withdrawal symptoms in adolescent smokers. Psychopharmacology, 90, 533-536.

Mermelstein, R. (2003). Teen smoking cessation. Tobacco Control, 12, 25-34.

Morrell, H. E. R., Cohen, L. M., \& al'Absi, M. (2008). Physiological and psychological symptoms and predictors in early nicotine withdrawal. Pharmacology, Biochemistry, and Behavior, 89, 272-278.

National Institute on Drug Abuse (2006). Research report series: Tobacco Addiction. National Institute of Health publication number 06-4342. Bethesda, MD: National Institute of Drug Abuse.

Noar, S. M. (2003). The role of structural equation modeling in scale development. Structural Equation Modeling, 10, 622-647.

Office of Applied Studies (2003). Results from the 2002 national survey on drug use and health: National findings. DHHS Publication No. SMA 03-3836, NHSDA Series H-22. Rockville, MD: Substance Abuse and Mental Health Services Administration. Office of Applied Studies (2006). Results from the 2005 national survey on drug use and health: National findings. NSDUH Series H-30, DHHS Publication No. SMA 06-4194. Rockville, MD: Substance Abuse and Mental Health Services Administration. 
O’Loughlin, J., DiFranza, J., Tyndale, R. F., Meshefedjian, G., McMillan-Davey, E., Clark, P. B., et al. (2003). Nicotine-dependence symptoms are associated with smoking frequency in adolescents. American Journal of Preventive Medicine, 26, 219-225.

Okoli, C. T. C., Browning, S., Rayens, M. K., \& Hahn, E. J. (2007). Secondhand tobacco smoke exposure, nicotine dependence, and smoking cessation. Public Health Nursing, 25, 46-56.

Pollak, C. P. (2003). Caffeine consumption and weekly sleep patterns in U.S. seventh-, eighth-, and ninth-graders. Pediatrics, 111, 42-46.

Prokhorov, A. V., DeMoor, C., Pallonen, U. E., Hudmon, K. S., Koehly, L, \& Hu, S. (2000). Validation of the modified fagerström tolerance questionnaire with salivary cotinine among adolescents. Addictive Behaviors, 25, 429-433.

Prokhorov, A., Hudmon, K. S., Cinciripini, P., \& Marani, S. (2005). "Withdrawal symptoms" in adolescents: A comparison of former smokers and never-smokers. Nicotine \& Tobacco Research, 7, 909-913.

Prokhorov, A. V., Hudmon, K. S., de Moor, C. A., Kelder, S. H., Conroy, J. L., \& Ordway, N. (2001). Nicotine dependence, withdrawal symptoms, and adolescents' readiness to quit smoking. Nicotine and Tobacco Research, 3, 151-155.

Prokhorov, A. V., Koehly, L. M. Pallonen, U. E., \& Hudmon, K. D. (1998). Adolescent nicotine dependence measured by the modified Fagerström tolerance questionnaire at two time points. Journal of Child and Adolescent Substance Abuse, 7, 35-47.

Prokhorov, A. V., Pallonen, U. E., Fava, J. L., Ding, L., \& Niaura, R. (1996). Measuring nicotine dependence among high-risk adolescent smokers. Addictive Behaviors, 21, 117-127. 
Riedel, B. W., Robinson, L. A., Klesges, R. C., \& McLain-Allen, B. (2002). Characteristics of adolescents caught with cigarettes at school: Implications for developing smoking cessation programs. Nicotine \& Tobacco Research, 4, 351-354.

Rojas, N. L., Killen. J. D., Haydel, F., \& Robinson, T. N. (1998). Nicotine dependence among adolescent smokers. Archives of Pediatric \& Adolescent Medicine, 152, 151-156.

Sussman, S. (2002). Effects of sixty six adolescent tobacco use cessation trials and seventeen prospective studies of self-initiated quitting. Tobacco Induced Diseases, 1, 35-81.

Tabachnick, B. G., \& Fidell, L. S. (1996). Using multivariate statistics ( $3^{\text {rd }}$ ed.). New York: Harper Collins Publishers, Inc.

Ulrich, J., Meyer, C., Hapke, U., Rumpf, H., \& Schumann (2004). Nicotine dependence, quit attempts, and quitting smoking in a regional population sample from a country with a high prevalence of tobacco smoking. Preventive Medicine, 38, 350-358.

United States Department of Health and Human Services (1988). The health consequences of smoking: Nicotine addiction, a report of the Surgeon General. Rockville, MD: United States Department of Health and Human Services, Public Health Service, Centers for Disease Control, Center for Health Promotion and Education, Office on Smoking and Health.

United States Department of Health and Human Services (1994). Preventing tobacco use among young people: A report of the Surgeon General. Atlanta, GA: United States Department of Health and Human Services, Public Health Service, Centers for Disease Control and Prevention, National Center for Chronic Disease Prevention and Health Promotion, Office on Smoking and Health. 
Unites States Department of Health and Human Services (2004). The health consequences of smoking: A report of the surgeon general. Atlanta, GA: United States Department of Health and Human Services, Centers for Disease Control and Prevention, National Center for Chronic Disease Prevention and Health Promotion, Office on Smoking and Health.

Wakefield, M. A., Chaloupka, F. J., Kaufman, N. J., Orleans, C. T., Barker, D. C., \& Ruel, E. E. (2000). Effect of restrictions on smoking at home, at school, and in public places on teenage smoking: Cross sectional study. British Medical Journal, 321, 333-337.

Wellman, R. J., DiFranza, J. R., Pbert, L., Fletcher, K. E., Flint, A., Young, M. H., et al. (2006). A comparison of the psychometric properties of the hooked on nicotine checklist and the modified fagerström tolerance questionnaire. Addictive Behaviors, 31, 486-495. 


\section{Footnotes}

${ }^{1}$ The original version of the mFTQ, the Fagerström Tolerance Questionnaire (Fagerström, 1978), or an updated version, the Fagerström Test for Nicotine Dependence (Heatherton et al., 1991), have also been utilized in studies examining this topic, although both were originally validated with an adult sample. 
Table 1

Selected smoker and nonsmokers characteristics

\begin{tabular}{ccc}
\hline & Smokers & Nonsmokers \\
\hline Total participants & 43 & 50 \\
Gender (female/male) & $24 / 19$ & $29 / 21$ \\
Mean age (years) & $17.2^{* *}$ & 16.2 \\
Mean weekday cigarettes smoked & 10.7 & -- \\
Mean weekend cigarettes smoked & 19.0 & -- \\
Daily servings of caffeine & $3.1 * *$ & 1.3 \\
Reside with a smoker & $65 \% * *$ & $22 \%$ \\
Secondhand smoke exposure outside the home & $81 \% * *$ & $14 \%$ \\
Smokeless tobacco use in the past month & $23 \% * *$ & $0 \%$ \\
Cigar use in the past month & $30 \% * *$ & $0 \%$ \\
Total study dropouts & $23 * *$ & 7 \\
\hline
\end{tabular}

$* * p \leq .01$

$* p<.05$ 
Table 2

Correlations of corresponding N-WAY and N-WAY Supplement Form items among smokers

\begin{tabular}{cc}
\hline Item & Correlation $(r)$ \\
\hline I was restless & $.51^{* *}$ \\
I was angry & $.44^{*}$ \\
I had headaches & $.69 * *$ \\
I had trouble concentrating & $.61 * *$ \\
I was alert & .27 \\
I was tired & .18 \\
I was stressed & $.32^{*}$ \\
I was hyper & $.72^{* *}$ \\
I was depressed & $.61^{* *}$ \\
I was nervous & $.55^{* *}$ \\
I was dizzy & $.80^{* *}$ \\
I woke up during my sleep & $.61 * *$ \\
I was irritable & $.37 *$ \\
I was hungry & $.53^{* *}$ \\
I had trouble falling asleep & $.73 * *$ \\
I had trouble getting along with my family & $.79 * *$ \\
I had trouble getting along with my friends & $.55^{* *}$ \\
I had trouble getting along with school staff & $.51^{* *}$ \\
I craved a cigarette & $.53^{* *}$ \\
Total scores & $.77^{* *}$ \\
\hline
\end{tabular}

$* * p \leq .01$

$* p<.05$ 
Table 3

Mean responses of smokers and nonsmokers on $N$-WAY symptom, $N$-WAY impact, and $N$-WAY Supplement Form items

\begin{tabular}{|c|c|c|c|c|c|c|}
\hline & \multicolumn{2}{|c|}{ N-WAY symptom items } & \multicolumn{2}{|c|}{ N-WAY impact items } & \multicolumn{2}{|c|}{ N-WAY Supplement Form } \\
\hline I was restless & 2.49 & 2.16 & 2.00 & 1.64 & $2.77 * *$ & 1.94 \\
\hline I had headaches & $2.50 * *$ & 1.70 & $2.19 * *$ & 1.58 & $2.77 * *$ & 1.82 \\
\hline I had trouble concentrating & 2.51 & 2.32 & $2.28 *$ & 1.80 & $2.69 * *$ & 2.10 \\
\hline I was alert & 2.70 & 2.64 & $2.07 * *$ & 1.44 & $2.70 * *$ & 3.34 \\
\hline I was hyper & $2.65^{*}$ & 2.08 & 1.86 & 1.54 & $2.74 *$ & 2.20 \\
\hline I was depressed & $2.67 * *$ & 1.80 & $2.45^{* *}$ & 1.62 & $2.63 * *$ & 1.70 \\
\hline I was nervous & 2.28 & 2.12 & 2.09 & 1.66 & $2.70 * *$ & 1.98 \\
\hline I was dizzy & $2.09 * *$ & 1.20 & $1.81 * *$ & 1.14 & $2.05 * *$ & 1.22 \\
\hline I woke up during my sleep & 2.47 & 2.20 & 1.98 & 1.58 & 2.40 & 2.04 \\
\hline I was irritable & $2.95^{* *}$ & 2.06 & $2.69 * *$ & 1.74 & $2.93 * *$ & 1.80 \\
\hline I had trouble getting along with my friends & $2.21 * *$ & 1.56 & $1.91 *$ & 1.44 & $2.14 * *$ & 1.46 \\
\hline I had trouble getting along with school staff & $2.21 * *$ & 1.38 & $1.90 * *$ & 1.32 & $2.19 * *$ & 1.42 \\
\hline I craved a cigarette & $3.35 * *$ & 1.04 & $2.57 * *$ & 1.00 & $3.35 * *$ & 1.02 \\
\hline Total score & $50.27 * *$ & 38.46 & $42.01 * *$ & 30.38 & $50.93 * *$ & 44.07 \\
\hline
\end{tabular}

$* * p \leq .01$

$* p<.05$ 
Table 4

$F$-values of the effect of age on $N$-WAY symptom, $N$-WAY impact, and N-WAY Supplement Form item differences between smokers and nonsmokers

\begin{tabular}{cccc}
\hline Item & N-WAY & N-WAY & N-WAY \\
symptom & impact & Supplement Form \\
\hline I was restless & 3.63 & $7.41^{*}$ & $5.64 *$ \\
I was angry & .46 & 1.27 & 2.69 \\
I had headaches & .22 & .44 & 2.50 \\
I was alert & 2.76 & 2.63 & .75 \\
I was tired & 2.03 & .00 & 2.78 \\
I was stressed & .40 & 1.56 & 3.40 \\
I was hyper & $7.41^{* *}$ & 3.92 & 3.02 \\
I was depressed & .09 & .04 & .62 \\
I was nervous & 3.77 & $7.93 * *$ & 2.53 \\
I was dizzy & 4.53 & $4.95 *$ & 2.49 \\
I woke up during my sleep & .33 & .12 & .03 \\
I was irritable & 1.37 & 3.37 & 1.75 \\
I was hungry & 3.20 & $7.23 * *$ & 2.88 \\
I had trouble falling asleep & 1.20 & 1.62 & .65 \\
I had trouble getting along with my family & 2.16 & .98 & .35 \\
I had trouble getting along with my friends & $7.36^{* *}$ & $9.93 * *$ & .37 \\
I had trouble getting along with school staff & .11 & .09 & $9.61 * *$ \\
I craved a cigarette & 1.05 & $4.89 *$ & .00 \\
Total score & $4.94 *$ & $6.32^{*}$ & 1.81 \\
\hline
\end{tabular}

$* * p \leq .01$

$* p<.05$ 
Table 5

Effect size values (partial $\eta^{2}$ ) of $N$-WAY symptom, $N$-WAY impact, and $N$-WAY Supplement Form item differences between smokers and nonsmokers, covarying age

\begin{tabular}{|c|c|c|c|}
\hline Item & $\begin{array}{c}\text { N-WAY symptom } \\
\text { (age/smoking status/ } \\
\text { total model) }\end{array}$ & $\begin{array}{c}\text { N-WAY impact } \\
\text { (age/smoking status/ } \\
\text { total model) }\end{array}$ & $\begin{array}{c}\text { N-WAY Supplement Form } \\
\text { (age/smoking status/ } \\
\text { total model) }\end{array}$ \\
\hline I was restless & $.04 / .00 / .05$ & $.08 * * / .01 / .11 * *$ & $.06 * / .09 * * / .19 * *$ \\
\hline I was angry & $.01 / .10^{* *} / .13^{* *}$ & $.01 / .08 * * / .12 * *$ & $.03 / .09 * * / .15 * *$ \\
\hline I had headaches & $.00 / .07 * * / .09 *$ & $.01 / .06 * / .08 *$ & $.03 / .12 * * / .18 * *$ \\
\hline I had trouble concentrating & $.03 / .00 / .04$ & $.03 / .03 / .07 *$ & $.01 / .06 * / .08 *$ \\
\hline I was alert & $.02 / .00 / .02$ & $.00 / .09 * * / .10 * *$ & $.03 / .09 * * / .10 * *$ \\
\hline I was tired & $.00 / .00 / .01$ & $.02 / .01 / .04$ & $.04 / .02 / .07 *$ \\
\hline I was stressed & $.07 * * / .01 / .11 * *$ & $.04 / .02 / .09 *$ & $.03 / .02 / .07 *$ \\
\hline I was hyper & $.00 / .05 * / .05$ & $.00 / .02 / .03$ & $.01 / .04 / .06$ \\
\hline I was depressed & $.04 / .07 * * / .14 * *$ & $.08 * * / .04 / .16 * *$ & $.03 / .10^{* * / .17 * *}$ \\
\hline I was nervous & $.05 * / .00 / .05$ & $.05 * / .02 / .09 *$ & $.03 / .09 * * / .15 * *$ \\
\hline I was dizzy & $.00 / .16^{* *} / .17 * *$ & $.00 / .13 * * / .15 * *$ & $.00 / .17 * * / .19 * *$ \\
\hline I woke up during my sleep & $.02 / .00 / .02$ & $.04 / .02 / .08 *$ & $.02 / .01 / .04$ \\
\hline I was irritable & $.03 / .07 * * / .13 * *$ & $.07 * * / .12 * * / .24 * *$ & $.03 / .18^{* *} / .25^{* *}$ \\
\hline I was hungry & $.01 / .00 / .02$ & $.02 / .08 * * / .13^{* *}$ & $.01 / .02 / .02$ \\
\hline I had trouble falling asleep & $.02 / .04 / .09 *$ & $.01 / .04 / .07 *$ & $.00 / .04 / .06$ \\
\hline I had trouble getting along with my family & $.00 / .03 / .17 *$ & $.01 / .03 / .05$ & $.00 / .08 * * / .10 * *$ \\
\hline I had trouble getting along with my friends & $.07 * * / .03 / .14 * *$ & $.10 * * / .01 / .14 * *$ & $.10 * * / .07 * * / .21 * *$ \\
\hline I had trouble getting along with school staff & $.00 / .13^{* *} / .14 * *$ & $.00 / .08 * * / .08 *$ & $.00 / .12 * * / .13 * *$ \\
\hline I craved a cigarette & $.01 / .64 * * / .68 * *$ & $.05 * / .42 * * / .50 * *$ & $.02 / .67 * * / .70 * *$ \\
\hline Total score & $.05 * / .16 * * / .25 * *$ & $.07 * * / .15 * * / .25 * *$ & $.06 * / .19 * * / .29 * *$ \\
\hline
\end{tabular}

\footnotetext{
$* * p \leq .01$
}

$* p<.05$ 
Table 6

$F$-values of the effect of daily caffeine use on $N$-WAY symptom, $N$-WAY impact, and N-WAY Supplement Form item differences between smokers and nonsmokers

\begin{tabular}{cccc}
\hline Item & N-WAY & N-WAY & N-WAY \\
symptom & impact & Supplement Form \\
\hline I was restless & $9.66^{* *}$ & $13.06^{* *}$ & $5.47 *$ \\
I was angry & $9.17^{* *}$ & $4.92^{*}$ & 3.06 \\
I had headaches & $5.46^{*}$ & 3.86 & 1.72 \\
I had trouble concentrating & $5.55^{*}$ & $6.03^{*}$ & $3.97 *$ \\
I was tired & 3.53 & .04 & 2.85 \\
I was stressed & 3.16 & 3.20 & .87 \\
I was hyper & 2.86 & .10 & 1.87 \\
I was depressed & 1.91 & 1.73 & .74 \\
I was nervous & .71 & 2.21 & 3.50 \\
I was dizzy & 2.18 & $4.42^{*}$ & 2.89 \\
I woke up during my sleep & $5.70 *$ & $4.02^{*}$ & $7.08^{* *}$ \\
I was irritable & 2.60 & 3.36 & 2.24 \\
I was hungry & 3.73 & 2.48 & 3.61 \\
I had trouble falling asleep & 3.25 & 2.51 & 2.84 \\
I had trouble getting along with my family & 1.57 & 2.27 & 1.43 \\
I had trouble getting along with my friends & 2.46 & 2.34 & 3.22 \\
I had trouble getting along with school staff & 2.97 & $3.65 *$ & $7.73 * *$ \\
I craved a cigarette & 1.24 & 3.16 & $12.38^{* *}$ \\
Total score & $15.42^{* *}$ & $8.27 * *$ & 3.15 \\
\hline
\end{tabular}

$* * p \leq .01$

$* p<.05$ 
Table 7

Effect size values (partial $\eta^{2}$ ) of $N$-WAY symptom, $N$-WAY impact, and $N$-WAY Supplement Form item differences between smokers and nonsmokers, covarying daily caffeine use

\begin{tabular}{|c|c|c|c|}
\hline Item & $\begin{array}{l}\text { N-WAY symptom } \\
\text { (daily caffeine use/smoking } \\
\text { status/total model) }\end{array}$ & $\begin{array}{l}\text { N-WAY impact (daily } \\
\text { caffeine use/smoking } \\
\text { status/total model) }\end{array}$ & $\begin{array}{l}\text { N-WAY Supplement Form } \\
\text { (daily caffeine use/ smoking } \\
\text { status/total model) }\end{array}$ \\
\hline I was restless & $.10 * * / .00 / .11 * *$ & $.13^{* *} / .00 / .16^{* *}$ & $.06 * / .07 * * / .19 * *$ \\
\hline I was angry & $.09 * * / .06 * / .21 * *$ & $.05 * / .06 * / .16 * *$ & $.03 / .08 * * / .16 * *$ \\
\hline I had headaches & $.06 * / .04 / .14 * *$ & $.04 / .03 / .11 * *$ & $.02 / .11 * * / .18 * *$ \\
\hline I had trouble concentrating & $.06 * / .00 / .06$ & $.06 * / .01 / .11 * *$ & $.04 * / .03 / .11 * *$ \\
\hline I was alert & $.04 / .00 / .04$ & $.00 / .09 * * / .10 * *$ & $.03 / .10 * * / .10 * *$ \\
\hline I was tired & $.03 / .00 / .04$ & $.03 / .01 / .06$ & $.01 / .02 / .05$ \\
\hline I was stressed & $.03 / .01 / .07 *$ & $.00 / .05 * / .05$ & $.02 / .02 / .06$ \\
\hline I was hyper & $.02 / .03 / .07 *$ & $.02 / .01 / .04$ & $.01 / .04 / .06$ \\
\hline I was depressed & $.01 / .07 * * / .11 * *$ & $.02 / .05 * / .10 * *$ & $.03 / .09 * * / .17 * *$ \\
\hline I was nervous & $.02 / .00 / .03$ & $.05 * / .01 / .08 *$ & $.03 / .07 * * / .15 * *$ \\
\hline I was dizzy & $.06 * / .09 * * / .21 * *$ & $.04 * / .09 * * / .18 * *$ & $.07 * * / .11 * * / .25 * *$ \\
\hline I woke up during my sleep & $.03 / .00 / .04$ & $.04 / .01 / .08 *$ & $.02 / .01 / .05$ \\
\hline I was irritable & $.04 / .05 * / .14 * *$ & $.03 / .12 * * / .20 * *$ & $.04 / .16^{* *} / .26^{* *}$ \\
\hline I was hungry & $.04 / .00 / .04$ & $.03 / .07 * * / .14 * *$ & $.03 / .03 / .04$ \\
\hline I had trouble falling asleep & $.02 / .04 / .08 *$ & $.03 / .03 / .08 *$ & $.02 / .03 / .07 *$ \\
\hline I had trouble getting along with my family & $.03 / .02 / .07 *$ & $.03 / .02 / .07 *$ & $.04 / .05 * / .13 * *$ \\
\hline I had trouble getting along with my friends & $.03 / .03 / .10 * *$ & $.04 / .02 / .08 *$ & $.08 * * / .06 * / .20 * *$ \\
\hline I had trouble getting along with school staff & $.05 * / .08 * * / .18 * *$ & $.03 / .04 / .11 * *$ & $.12 * * / .05 * / .23 * *$ \\
\hline I craved a cigarette & $.01 / .63 * * / .68 * *$ & $.03 / .40 * * / .49 * *$ & $.03 / .65 * * / .71 * *$ \\
\hline Total score & $.15 * * / .11 * * / .33 * *$ & $.08 * * / .12 * * / .27 * *$ & $.11 * * / .16 * * / .33 * *$ \\
\hline
\end{tabular}

\footnotetext{
$* * p \leq .01$
}

$* p<.05$ 
Table 8

$F$-values of $N$-WAY symptom, $N$-WAY impact, and N-WAY Supplement Form item differences between smokers and nonsmokers, covarying age and daily caffeine use

\begin{tabular}{|c|c|c|c|}
\hline Item & $\begin{array}{l}\text { N-WAY } \\
\text { symptom }\end{array}$ & $\begin{array}{c}\text { N-WAY } \\
\text { impact }\end{array}$ & $\begin{array}{c}\text { N-WAY } \\
\text { Supplement Form }\end{array}$ \\
\hline I was restless & .33 & 3.89 & .12 \\
\hline I was angry & $4.12 *$ & $4.70 *$ & 3.56 \\
\hline I had headaches & 2.76 & $7.88 * *$ & 2.15 \\
\hline I had trouble concentrating & .48 & 2.10 & .32 \\
\hline I was alert & .69 & $11.99 * *$ & $8.19 * *$ \\
\hline I was tired & .04 & .67 & .16 \\
\hline I was stressed & .13 & .63 & 2.24 \\
\hline I was hyper & 2.45 & 2.34 & .67 \\
\hline I was depressed & $4.07 *$ & $5.64 *$ & 1.60 \\
\hline I was nervous & .35 & $4.55^{*}$ & .13 \\
\hline I was dizzy & $9.55 * *$ & $10.34 * *$ & $7.49 * *$ \\
\hline I woke up during my sleep & .01 & .21 & .36 \\
\hline I was irritable & 2.83 & $12.31 * *$ & $7.55 * *$ \\
\hline I was hungry & .32 & 3.12 & $4.50 *$ \\
\hline I had trouble falling asleep & 1.86 & 2.02 & 1.54 \\
\hline I had trouble getting along with my family & 1.23 & $4.02 *$ & 1.23 \\
\hline I had trouble getting along with my friends & .98 & 2.37 & .13 \\
\hline I had trouble getting along with school staff & $7.50 * *$ & $4.61 *$ & 3.94 \\
\hline I craved a cigarette & $131.57 * *$ & $143.32 * *$ & $48.54 * *$ \\
\hline Total score & $7.07 * *$ & $7.49 * *$ & $11.01 * *$ \\
\hline
\end{tabular}

$* * p \leq .01$

$* p<.05$ 
Table 9

Effect size values (partial $\eta^{2}$ ) of $N$-WAY symptom, $N$-WAY impact, and $N$-WAY Supplement Form item differences between smokers and nonsmokers, covarying age and daily caffeine use

\begin{tabular}{|c|c|c|c|}
\hline Item & $\begin{array}{c}\text { N-WAY symptom } \\
\text { (age/daily caffeine use/ } \\
\text { smoking status/total model) }\end{array}$ & $\begin{array}{l}\text { N-WAY impact (age/ daily } \\
\text { caffeine use/ smoking } \\
\text { status/total model) }\end{array}$ & $\begin{array}{l}\text { N-WAY Supplement Form } \\
\text { (age/daily caffeine use/ } \\
\text { smoking status/total model) }\end{array}$ \\
\hline I was restless & $.04 / .10 * * / .00 / .15 * *$ & $.08 * * / .13 * * / .00 / .23 * *$ & $.06 * / .06 * / .04 / .24 * *$ \\
\hline I was angry & $.01 / .09 * * / .04 * / .21 * *$ & $.01 / .05 * / .04 / .17 * *$ & $.03 / .03 / .05 * / .18 * *$ \\
\hline I had headaches & $.00 / .06 * / .03 / .14 * *$ & $.01 / .04 / .02 / .11 * *$ & $.03 / .02 / .08 * * / .20 * *$ \\
\hline I had trouble concentrating & $.03 / .06 * / .00 / .09 *$ & $.03 / .06 * / .00 / .13 * *$ & $.01 / .04 / .02 / .12 * *$ \\
\hline I was alert & $.02 / .04 / .01 / .06$ & $.00 / .00 / .08 * * / .10 *$ & $.03 / .03 / .12 * * / .13 * *$ \\
\hline I was tired & $.01 / .03 / .00 / .04$ & $.02 / .03 / .00 / .08$ & $.04 * / .01 / .01 / .08$ \\
\hline I was stressed & $.08 * * / .03 / .00 / .14 * *$ & $.04 / .00 / .03 / .09 *$ & $.03 / .02 / .01 / .09 *$ \\
\hline I was hyper & $.00 / .02 / .03 / .07$ & $.00 / .02 / .01 / .04$ & $.01 / .01 / .03 / .07$ \\
\hline I was depressed & $.04 / .01 / .04 * / .14 * *$ & $.08 * * / .03 / .02 / .18 * *$ & $.03 / .04 / .06 * / .20 * *$ \\
\hline I was nervous & $.05 * / .02 / .00 / .07$ & $.05 * / .05 / * / .00 / .13 * *$ & $.03 / .03 / .05 * / .17 * *$ \\
\hline I was dizzy & $.00 / .06 * / .10 * * / .22 * *$ & $.00 / .04 / .08 * * / .19 * *$ & $.00 / .07 * * / .10 * * / .25 * *$ \\
\hline I woke up during my sleep & $.02 / .03 / .00 / .05$ & $.04 / .04 / .00 / .11^{*}$ & $.02 / .02 / .00 / .07$ \\
\hline I was irritable & $.03 / .04 / .03 / .17 * *$ & $.08 * * / .03 / .08 * * / .26 * *$ & $.03 / .04 / .12 * * / .28 * *$ \\
\hline I was hungry & $.01 / .03 / .00 / .05$ & $.02 / .03 / .05 * / .15 * *$ & $.01 / .03 / .03 / .05$ \\
\hline I had trouble falling asleep & $.02 / .02 / .02 / .10 *$ & $.01 / .02 / .02 / .09^{*}$ & $.00 / .02 / .02 / .07$ \\
\hline I had trouble getting along with my family & $.00 / .03 / .01 / .07$ & $.01 / .03 / .01 / .08$ & $.00 / .03 / .04 * / .13 * *$ \\
\hline I had trouble getting along with my friends & $.08 * * / .03 / .01 / .17 * *$ & $.10 * * / .04 / .00 / .18 * *$ & $.10 * * / .08 * * / .03 / .28 * *$ \\
\hline I had trouble getting along with school staff & $.00 / .05 * / .08 * * / .18 * *$ & $.00 / .03 / .04 / .11 * *$ & $.00 / .12 * * / .05 * / .23 * *$ \\
\hline I craved a cigarette & $.01 / .01 / .60 * * / .68 * *$ & $.05 * / .03 / .35 * * / .51 * *$ & $.02 / .03 / .62 * * / .71 * *$ \\
\hline Total score & $.06 * / .15 * * / .07 * * / .36 * *$ & $.06 * / .11 * * / .11 * * / .37 * *$ & $.07 * * / .09 * * / .08 * * / .32 * *$ \\
\hline
\end{tabular}

\footnotetext{
$* * p \leq .01$
}

$* p<.05$ 
Table 10

F-values of N-WAY Supplement Form item differences between heavy and light smokers, light and nonsmokers, and heavy and nonsmokers, covarying age and daily caffeine use as necessary

\begin{tabular}{cccc}
\hline Item & $\begin{array}{c}\text { Heavy vs. light } \\
\text { smokers }\end{array}$ & $\begin{array}{c}\text { Light vs. } \\
\text { nonsmokers }\end{array}$ & $\begin{array}{c}\text { Heavy vs. } \\
\text { nonsmokers }\end{array}$ \\
\hline I was restless & 2.77 & $5.67 *$ & 1.09 \\
I was angry & $4.23^{*}$ & $6.01^{*}$ & 1.58 \\
I had headaches & .16 & 1.98 & $7.49^{* *}$ \\
I was alert & 1.92 & $4.68^{*}$ & .66 \\
I was tired & .78 & 2.12 & $8.58^{* *}$ \\
I was stressed & 2.17 & $4.33^{*}$ & .01 \\
I was hyper & .05 & .46 & .62 \\
I was depressed & 3.68 & $6.84 *$ & .35 \\
I was nervous & .36 & $6.15^{*}$ & 3.39 \\
I was dizzy & .26 & $7.15^{* *}$ & $4.68 *$ \\
I woke up during my sleep & 3.00 & $19.57 * *$ & $4.40^{*}$ \\
I was irritable & .57 & 1.39 & .04 \\
I was hungry & .64 & $7.40 * *$ & $8.43 * *$ \\
I had trouble falling asleep & .16 & .01 & 3.52 \\
I had trouble getting along with my family & .24 & .96 & 1.70 \\
I had trouble getting along with my friends & .21 & $5.04 *$ & 2.69 \\
I had trouble getting along with school staff & .28 & $7.34 * *$ & 2.35 \\
I craved a cigarette & .32 & $121.63^{*}$ & 2.97 \\
Total score & 1.07 & $16.99 * *$ & $161.00^{* *}$ \\
\hline
\end{tabular}

$* * p \leq .01$

$* p<.05$ 
Table 11

Effect size values (partial $\eta^{2}$ ) of $N$-WAY Supplement Form item differences between heavy and light smokers, light and nonsmokers, and heavy and nonsmokers, covarying age and daily caffeine use as necessary

\begin{tabular}{|c|c|c|c|}
\hline Item & $\begin{array}{l}\text { Heavy vs. light smokers } \\
\text { (smoking status) }\end{array}$ & $\begin{array}{l}\text { Light vs. nonsmokers } \\
\text { (daily caffeine use/ } \\
\text { smoking status) }\end{array}$ & $\begin{array}{c}\text { Heavy vs. nonsmokers } \\
\text { (age/daily caffeine use/ } \\
\text { smoking status) }\end{array}$ \\
\hline I was restless & .06 & $.07 * / .09 *$ & $.07 * / .08 * / .01$ \\
\hline I was angry & $.09 *$ & $.02 / .09 *$ & $.03 / .04 / .02$ \\
\hline I had headaches & .00 & $.02 / .03$ & $.02 / .03 / .09 * *$ \\
\hline I had trouble concentrating & .05 & $.00 / .08 *$ & $.00 / .06 * / .01$ \\
\hline I was alert & .02 & $.01 / .04$ & $.03 / .03 / .10 * *$ \\
\hline I was tired & .05 & $.00 / .07 *$ & $.03 / .02 / .00$ \\
\hline I was stressed & .00 & $.01 / .01$ & $.01 / .03 / .01$ \\
\hline I was hyper & .08 & $.00 / .11 * *$ & $.01 / .02 / .00$ \\
\hline I was depressed & .01 & $.00 / .10 *$ & $.02 / .04 / .04$ \\
\hline I was nervous & .01 & $.04 / .11 * *$ & $.01 / .04 / .06^{*}$ \\
\hline I was dizzy & .07 & $.01 / .25 * *$ & $.01 / .10 * * / .05 *$ \\
\hline I woke up during my sleep & .01 & $.00 / .02$ & $.01 / .03 / .00$ \\
\hline I was irritable & .02 & $.05 / .11^{* *}$ & $.03 / .05 * / .10 * *$ \\
\hline I was hungry & .00 & $.01 / .00$ & $.01 / .04 / .04$ \\
\hline I had trouble falling asleep & .01 & $.02 / .02$ & $.00 / .02 / .02$ \\
\hline I had trouble getting along with my family & .01 & $.00 / .08 *$ & $.01 / .04 / .03$ \\
\hline I had trouble getting along with my friends & .00 & $.02 / .11 * *$ & $.05 / .12 * * / .03$ \\
\hline I had trouble getting along with school staff & .01 & $.03 / .08 *$ & $.00 / .13 * * / .04$ \\
\hline I craved a cigarette & .01 & $.03 / .68 * *$ & $.04 / .06 * / .67 * *$ \\
\hline Total score & .03 & $.01 / .23 * *$ & $.04 / .13 * * / .07 *$ \\
\hline
\end{tabular}

\footnotetext{
$* * p \leq .01$

$* p<.05$
} 
Table 12

Item analysis of $N$-WAY symptom items

\begin{tabular}{ccc}
\hline Item & $\begin{array}{c}\text { Corrected Item-Total } \\
\text { Correlation }\end{array}$ & $\begin{array}{c}\text { Scale Variance if } \\
\text { Deleted }\end{array}$ \\
\hline I was restless & .58 & 137.72 \\
I was angry & .37 & 143.93 \\
I had headaches & .42 & 141.55 \\
I had trouble concentrating & .62 & 136.97 \\
I was alert & -.01 & 156.77 \\
I was tired & .36 & 145.33 \\
I was stressed & .47 & 139.78 \\
I was hyper & .29 & 147.26 \\
I was depressed & .61 & 136.58 \\
I was nervous & .52 & 139.56 \\
I was dizzy & .28 & 146.45 \\
I woke up during my sleep & .46 & 139.96 \\
I was irritable & .66 & 134.91 \\
I was hungry & .08 & 153.99 \\
I had trouble falling asleep & .56 & 137.68 \\
I had trouble getting along with my family & .59 & 137.08 \\
I had trouble getting along with my friends & .40 & 142.39 \\
I had trouble getting along with school staff & .33 & 145.66 \\
I craved a cigarette & .35 & 146.46 \\
\hline
\end{tabular}

Total scale variance $=157.51$ 
Table 13

Item analysis of N-WAY impact items

\begin{tabular}{|c|c|c|}
\hline Item & $\begin{array}{l}\text { Corrected Item-Total } \\
\text { Correlation }\end{array}$ & $\begin{array}{c}\text { Scale Variance if } \\
\text { Deleted }\end{array}$ \\
\hline How much did being restless disrupt my life & .56 & 190.35 \\
\hline How much did being angry disrupt my life & .52 & 188.99 \\
\hline $\begin{array}{l}\text { How much did having headaches disrupt my } \\
\text { life }\end{array}$ & .52 & 186.84 \\
\hline $\begin{array}{l}\text { How much did having trouble concentrating } \\
\text { disrupt my life }\end{array}$ & .68 & 182.94 \\
\hline How much did being alert disrupt my life & .41 & 192.61 \\
\hline How much did being tired disrupt my life & .53 & 188.66 \\
\hline How much did being stressed disrupt my life & .51 & 186.67 \\
\hline How much did being hyper disrupt my life & .58 & 186.23 \\
\hline $\begin{array}{l}\text { How much did being depressed disrupt my } \\
\text { life }\end{array}$ & .66 & 180.02 \\
\hline How much did being nervous disrupt my life & .59 & 184.34 \\
\hline How much did being dizzy disrupt my life & .50 & 189.95 \\
\hline $\begin{array}{l}\text { How much did waking up during my sleep } \\
\text { disrupt my life }\end{array}$ & .58 & 186.36 \\
\hline How much did being irritable disrupt my life & .77 & 184.98 \\
\hline How much did being hungry disrupt my life & .58 & 186.20 \\
\hline $\begin{array}{l}\text { How much did having trouble falling asleep } \\
\text { disrupt my life }\end{array}$ & .60 & 184.27 \\
\hline $\begin{array}{l}\text { How much did having trouble getting along } \\
\text { with my family disrupt my life }\end{array}$ & .71 & 180.30 \\
\hline $\begin{array}{l}\text { How much did having trouble getting along } \\
\text { with my friends disrupt my life }\end{array}$ & .47 & 188.40 \\
\hline $\begin{array}{l}\text { How much did having trouble getting along } \\
\text { with school staff disrupt my life }\end{array}$ & .54 & 186.32 \\
\hline How much did cravings disrupt my life & .66 & 182.94 \\
\hline
\end{tabular}

Total scale variance $=206.46$ 
Table 14

Exploratory factor analysis of $N-W A Y$ items

\begin{tabular}{|c|c|}
\hline N-WAY Item & Eigenvalues \\
\hline I was restless & .38 \\
\hline How much did being restless disrupt my life & .66 \\
\hline I was angry & .38 \\
\hline How much did being angry disrupt my life & .56 \\
\hline I had headaches & .53 \\
\hline How much did having headaches disrupt my life & .57 \\
\hline I had trouble concentrating & .59 \\
\hline How much did having trouble concentrating disrupt my life & .75 \\
\hline I was alert & -.07 \\
\hline How much did being alert disrupt my life & .45 \\
\hline I was tired & .30 \\
\hline How much did being tired disrupt my life & .52 \\
\hline I was stressed & .53 \\
\hline How much did being stressed disrupt my life & .55 \\
\hline I was hyper & .28 \\
\hline How much did being hyper disrupt my life & .56 \\
\hline I was depressed & .69 \\
\hline How much did being depressed disrupt my life & .71 \\
\hline I was nervous & .70 \\
\hline How much did being nervous disrupt my life & .60 \\
\hline I was dizzy & .26 \\
\hline How much did being dizzy disrupt my life & .43 \\
\hline I woke up during my sleep & .42 \\
\hline How much did waking up during my sleep disrupt my life & .58 \\
\hline I was irritable & .56 \\
\hline How much did being irritable disrupt my life & .77 \\
\hline I was hungry & -.02 \\
\hline How much did being hungry disrupt my life & .55 \\
\hline I had trouble falling asleep & .57 \\
\hline How much did having trouble falling asleep disrupt my life & .64 \\
\hline I had trouble getting along with my family & .68 \\
\hline How much did having trouble getting along with my family disrupt my life & .71 \\
\hline I had trouble getting along with my friends & .35 \\
\hline How much did having trouble getting along with my friends disrupt my life & .48 \\
\hline I had trouble getting along with school staff & .34 \\
\hline How much did having trouble getting along with school staff disrupt my life & .51 \\
\hline I craved a cigarette & .34 \\
\hline How much did cravings disrupt my life & .63 \\
\hline
\end{tabular}




\section{Appendix A}

\section{Demographics Form}

\section{Please complete the following items about yourself}

A. Date of birth:

B. Gender

1. Male

2. Female

C. Ethnicity:

1. African American

2. Asian

3. Caucasian/European American

4. Hispanic

5. Indian

6. Native American

7. Other:

D. Grade

1. $7^{\text {th }}$ grade

2. $8^{\text {th }}$ grade

3. $9^{\text {th }}$ grade

4. $10^{\text {th }}$ grade

5. $11^{\text {th }}$ grade

6. $12^{\text {th }}$ grade

7. I do not currently attend school

E. City and state of residence:

F. Does another member of your household regularly smoke cigarettes? Yes

a. If yes, how many members of your household smoke cigarettes?

b. Who in your household smokes (select all that apply)?

1. Mother

2. Father

3. Sister

4. Brother

5. Step-parent

6. Step-sibling

7. Other:

G. Are you regularly exposed to any other secondhand smoke outside your home?

a. If yes, please describe: 


\section{Appendix B}

\section{Smoking Information Form}

1. Have you smoked at least one cigarette:

$\begin{array}{lll}\text { a. In the past year? } & \text { Yes No }\end{array}$

$\begin{array}{lll}\text { a. In the past } 30 \text { days? } & \text { Yes } & \text { No }\end{array}$

$\begin{array}{lll}\text { b. In the past } 7 \text { days? } & \text { Yes }\end{array}$

2. Do you smoke almost every day? $\quad$ Yes No

3. How many cigarettes do you currently smoke on a typical WEEKDAY? _ _ cigarettes a day

4. How many cigarettes do you currently smoke on a typical WEEKEND? _ _ cigarettes a day

5. How long have you been a smoker (smoking at least one cigarette a month)?

6. Have you ever attempted to quit cigarettes before (circle one)? Yes No

6a. If yes, how many quit attempts?

6b. When was your last quit attempt?

7. Have you used smokeless tobacco (ex: chew, spit, dip, snuff) in the past 30 days?

Yes $\quad$ No

7a. If yes, how often do you use smokeless tobacco? Daily Occasionally

7b. If daily, how many packages or cans a day? packages/cans a day

8. Have you smoked cigars in the past 30 days? $\quad$ Yes No

8a. If yes, how often do you smoke cigars? Daily Occasionally

8b. If daily, how many cigars a day? cigars a day

9. Have you consumed caffeine in the past week? $\quad$ Yes No

9a. If yes, how many caffeinated beverages (e.g., $12 \mathrm{oz}$. of soda, $8 \mathrm{oz}$. of coffee) do you consume each day, on average? caffeinated beverages a day 


\section{Appendix C}

Nicotine Withdrawal Assessment for Youth (N-WAY)

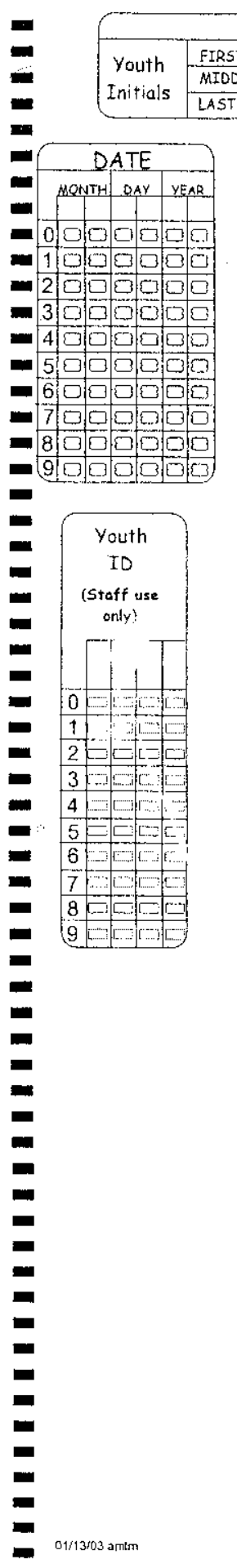

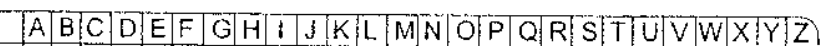

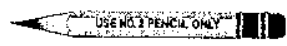

MAODE E

N-WAY

Correct Mark

$\square \square \square$

incorrect Marks

$\infty \infty$

\section{Nicotine Withdrawal Assessment for Youth}

INSTRUCTIONS: Answer the questions below by marking the response that best fits you.

During the past $\underline{7}$ days: [Choose only $\underline{1}$ answer for each question.]

1. I was restless

$\square$ Rarely

$\square$ Somewhat less than usual

$\square$ About the same as usual

b. Somewhat more than usual

$\square$ Much more than usual

1a. How much did being restless disrupt my life?
$\because$ Not at all
$\square$ A littlos
$\square$ Somewhat
$\square$ A lot
$\square$ Extremely

2. I was angry

$\square$ Rarely

C. Somewhat less than usua

$\square$ About the same as usual

$\square$ Somewhat more than usual

$\checkmark$ Much more than usual

2. How much did being angry disrupt my life?
?] Not at al
$\square$ Alittle
$\square$ Somewhat
a A lot
Extremely

3. I had headaches
$\square$ Rarely
$\square$ Somewhat less than usual
$\square$ About the same as usual
$\square$ Somewhat more than usual
$\square$ Much more than usual

3a. How much did headaches disrupt my life?
C Not at all
[. A little
$\square$ Somewhat
$\square$ A lot
$\square$ Extremely 


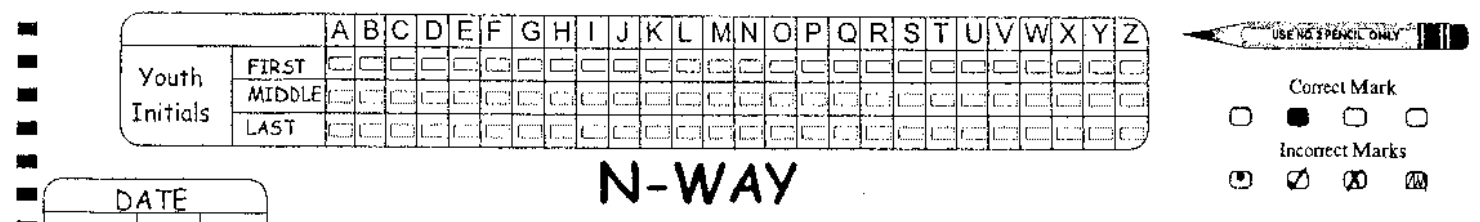

During the past $\underline{Z}$ days: [Choose only 1 answer for each question.]

$-0,0,030,0$

- 1

2. 口.

$=300 \square \square \square$

-5 В

- $6 \square \square \square \square$

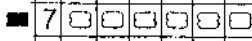

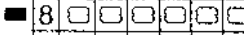

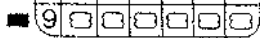

=

$=$

- routh

w ID

- (Staff use

- only)

m

=

m

.1.

1

-

$=$

둔

$=$

a.

网

an

-

(1)

$=$

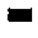

a

iv

-

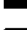

$=$

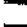

드.

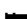

들

ㅍ.

-

01/13/03 andm
4. I had trouble concentrating

$\square$ Rarely

Somewhat less than usuat

$\square$ About the same as usual

c) Somewhat more than usual

$\square$ Much more than usual

4a. How much did having trouble concentrating disrupt my life?
$\checkmark$ Not at all
$\square$ A little
Somewhat
$\square$ A lot
$\square$ Extremely

5. I was alert

$\square$ Rarely

$\square$ Somewhat less than usual

$\square$ About the same as usual

$\checkmark$ Somewhat more than usual

$\square$ Much more than usual

5a. How much did being alert disrupt my life?
$\square$ Not at all
a A little
Somewhat
C A tot
$\square$ Extremely
6. I was tired
$\square$ Rarely
$\square$ Somewhat iess than usual
$\square$ About the same as usual
$\square$ Somewhat more than usual
$\square$ Much more than usual

6a. How much did being tired disrupt my life?
Not at all
0 A little
$\square$ Somewhat
$\square$ A lot
$\square$ Extremely 


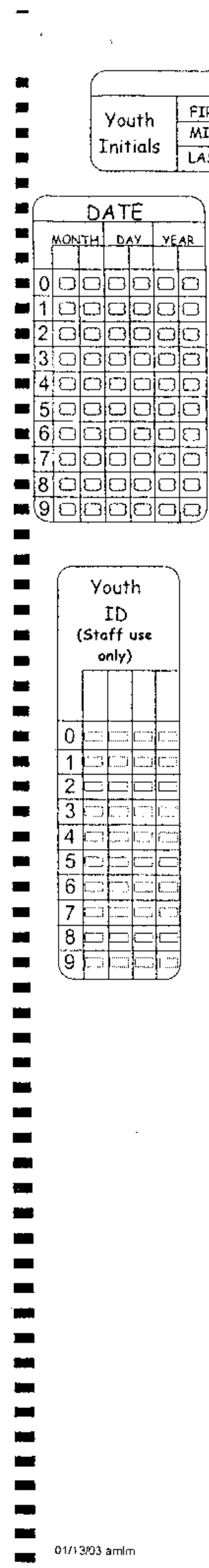

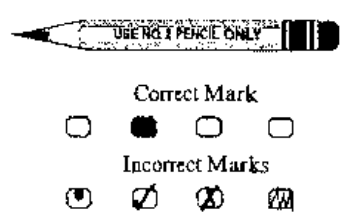

N-WAY

During the past $\underline{7}$ days: [Choose only $\underline{1}$ answer for each question.]
7. I was stressed
$\square$ Rarely
$\square$ Somewhat less than usual
$\square$ About the same as usual
$\checkmark$ Somewhat more than usual
$\checkmark$ Much more than usual

7a. How much did being stressed disrupt my life?
Not at all
$\square$ A little
Somewhat
$\checkmark$ A lot
$\square$ Extremely

8. I was hyper
$\square$ Rarely
$\square$ Somewhat less than usual
About the same as usual
$\checkmark$ Somewhat more than usual
$\square$ Much more than usual

8a. How much did being hyper disrupt my life?
$\square$ Not at all
(3) A little
$\checkmark$ Somewhat
$\square$ A lot
$\square$ Extremely

9. I was depressed

$\square$ Rarely

$\square$ Somewhat less than usual

- About the same as usual

0 Somewhat more than usual

Much more than usual

9a. How much did being depressed disrupt my life?
$\square$ Not at all
\&.) A little
$\checkmark$ Somewhat
$\square$ A lot
$\square$ Extremely 


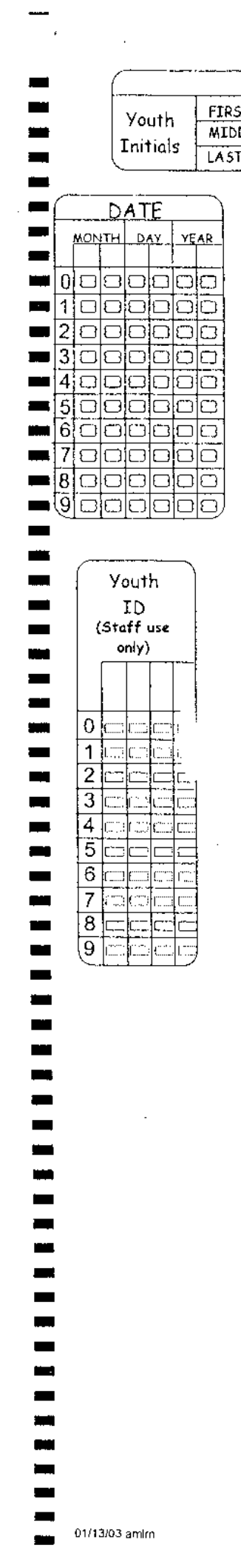

A

\begin{tabular}{|c|c|c|c|c|c|c|c|c|c|c|c|c|c|c|c|c|c|c|c|c|c|c|c|}
\hline $25 T$ & $E \square$ & $\square$ & $\therefore$ & 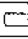 & $\square$ & $\square$ & 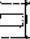 & & $E-1$ & 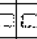 & $d=$ & $=$ & $\leftarrow$ & & 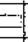 & & $\square$ & E & + & & $=$ & 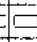 & 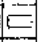 \\
\hline$L E$ & 10 & $i$ & $i$ & $F$ & 10 & $d$ & 1 & & $t_{1}$ & 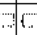 & 11 & 1, & 6 & & & & & 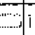 & i & & $\alpha \frac{1}{1}$ & & \\
\hline 51 & {$[1$} & $1 \ldots$ & $1+\cdots$ & 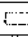 & 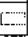 & $\square$ & 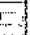 & 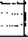 & 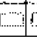 & 4 & {$[\cdots$} & 16 & 13 & 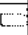 & & $\cdots$ & 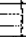 & in & D. & & 11 & & 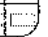 \\
\hline
\end{tabular}

N-WAY

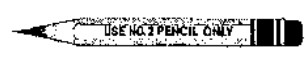

Correct Mark

$\square$ incorrect Marks

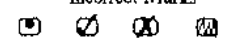

During the past $\underline{Z}$ days: [Choose only 1 answer for each question.]

10. I was nervous

$\square$ Rarely

$\square$ Somewhat less than usual

About the same as usual

$\square$ Somewhat more than usual

O Much more than usua!

10a. How much did being nervous disrupt my life?
$\square$ Not at all
$\square$ A little
Somewhat
$\square$ Alot
$\square$ Extremely

11. I was dizzy

B Rarely

$\square$ Somewhat less than usual

$\square$ About the same as usual .

$\square$ Somewhat more than usual

$\square$ Much more than usual

11a. How much did being dizzy disrupt my life?
Not at all
A little
$\square$ Somewhat
$\square$ Alot
Extremely

12. I woke up during my sleep

$\square$ Rirely

$\square$ So rewhat less than usual

$\square$ Al wit the same as usual

$\square$ Somewhat more than usual

$\square$ Much more than usua:

12a. How much did waking up during my sleep disrupt my life?

$\square$ Not at all

$\square$ A little

$\square$ Somewhat

$\square$ A lot

$\square$ Extremely

page 4 of 10 


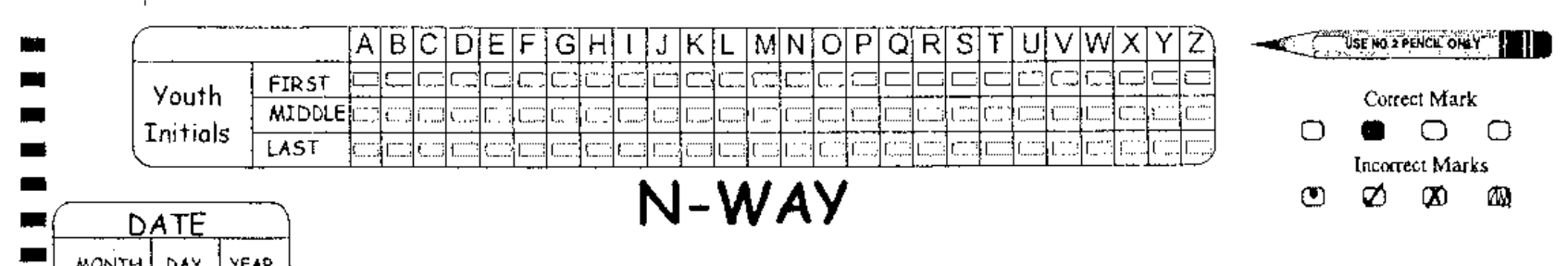

During the past $\underline{Z}$ days: [Choose only 1 answer for each question.]

13. I was irritable
$\square$ Rarely
$\square$ Somewhat less than usual
$\square$ About the same as usual
$\square$ Somewhat more than usual
$\checkmark$ Much more than usual

13a. How much did being irritable disrupt my life?
$\square$ Not at all
$\square$ A little
$\square$ Somewhat
$\square$ A tot
$\square$ Extremely

14. I was hungry
$\square$ Rarely
$\square$ Somewhat less than usual
$\square$ About the same as usual
$\square$ Somewhat more than usual
[3 Much more than usual

14a. How much did being hungry disrupt my life?
$\square$ Not at all
$\checkmark$ A little
Somewhat
A lot
G Extremely

\section{I had trouble falling asleep \\ $\square$ Rarely \\ $\square$ Somewhat less than usual \\ About the same as usual \\ $\square$ Somewhat more than usua! \\ $\square$ Much more than usua?}

15a. How much did having trouble falling asleep disrupt my life?
$\square$ Not at all
$\square$ A little
Somewhat
A lot
$\square$ Extremely 


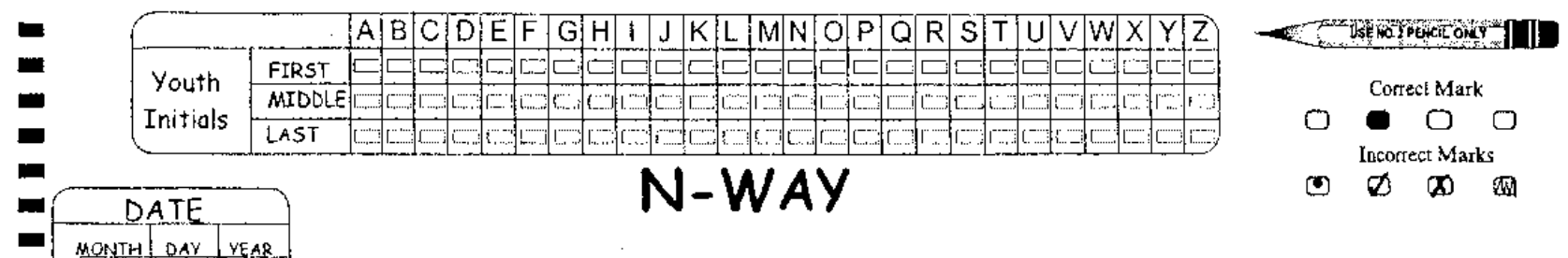

During the past $\underline{Z}$ days: [Choose only $\underline{1}$ answer for each question.]

16. I had trouble getting along with my family

$\square$ Rarely

8 Somewhat less than usual

$\square$ About the same as usual

$\checkmark$ Somewhat more than usual

$\square$ Much more than usual

16a. How much did having trouble getting along with my family disrupt my life?
$\square$ Not at all
$\square$ A little
$\square$ Somewhat
$\square$ Alot
$\square$ Extremely

16b. Generally, the intensity of trouble getting along with my family was:

$$
\begin{array}{cccccccccc}
\square & \square & \square & \square & \square & \square & \square & \square & \square & \square \\
1 & 2 & 3 & 4 & 5 & 6 & 7 & 8 & 9 & 10 \\
\text { MORSTEVR }
\end{array}
$$

16c. Generally, trouble getting along with my family occurred:

$\square$ Early in Morning/Before School (6am-10am)

$\square$ Mid day (11am-1pm)

$\checkmark$ Afternoon (2pm-3pm)

(1) Late Afternoon/After School (4pm-6pm)

0. Early Evening/After Dinner (6pm-8pm)

$\square$ Late Evening (9pm-1am)

$\square$ No particular time 


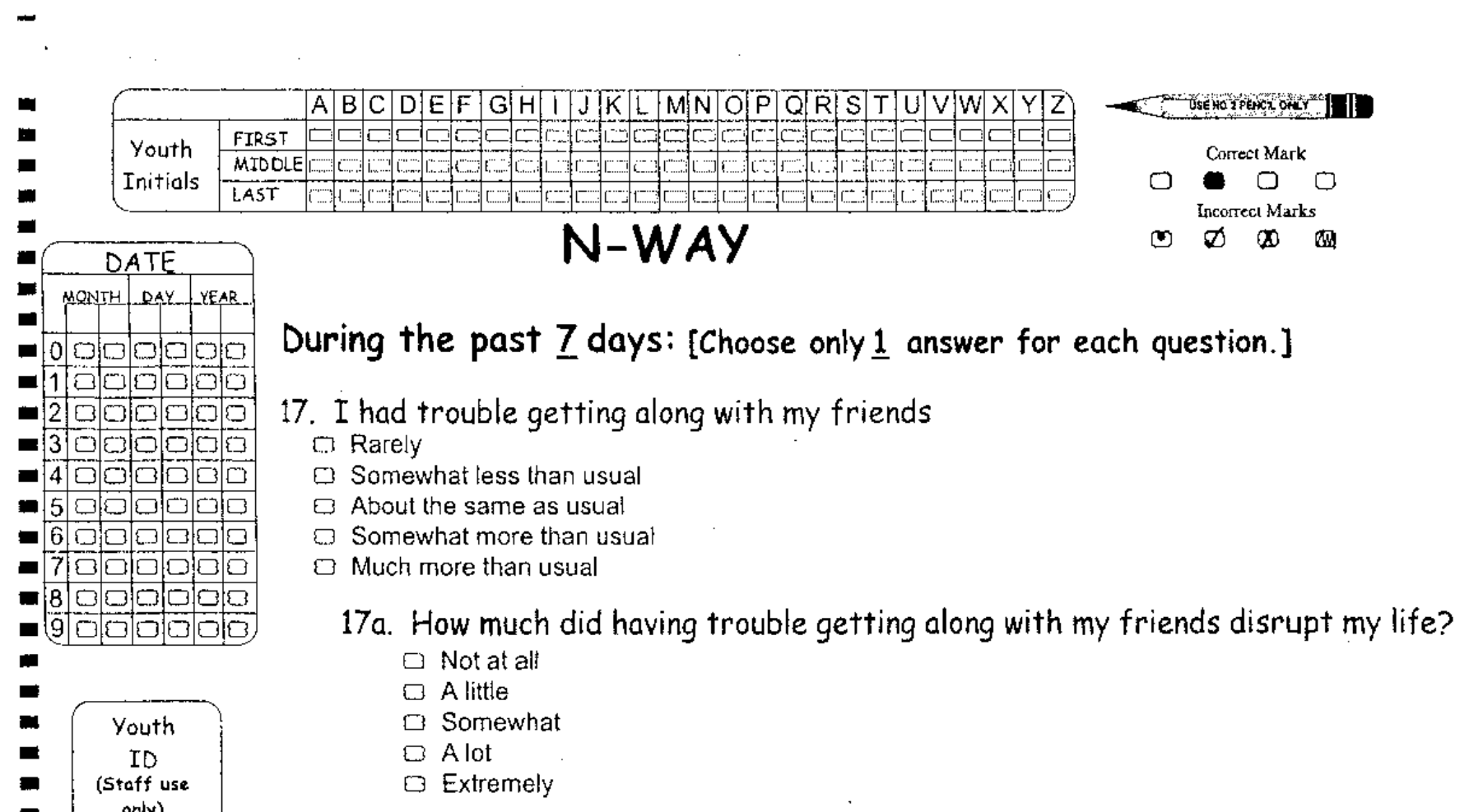

17b. Generally, the intensity of trouble getting along with my friends was:

$$
\begin{array}{cccccccccc}
\square & \square & \square & \square & \square & \square & \square & \square & 9 & \square \\
1 & 2 & 3 & 4 & 5 & 6 & 7 & 8 & 9 & 10 \\
\text { WORST EVER } &
\end{array}
$$

17c. Generally, trouble getting along with my friends occurred:

$\square$ Early in Morning/Before School (6am-10am)

$\checkmark$ Mid day (11am-1pm)

0 Afternoon (2pm-3pm)

0 Late Afternoon/After School (4pm-6pm)

$\square$ Early Evening/After Dinner (6pm-8pm)

$\square$ Late Evening (9pm+1am)

$\square$ No particular time 


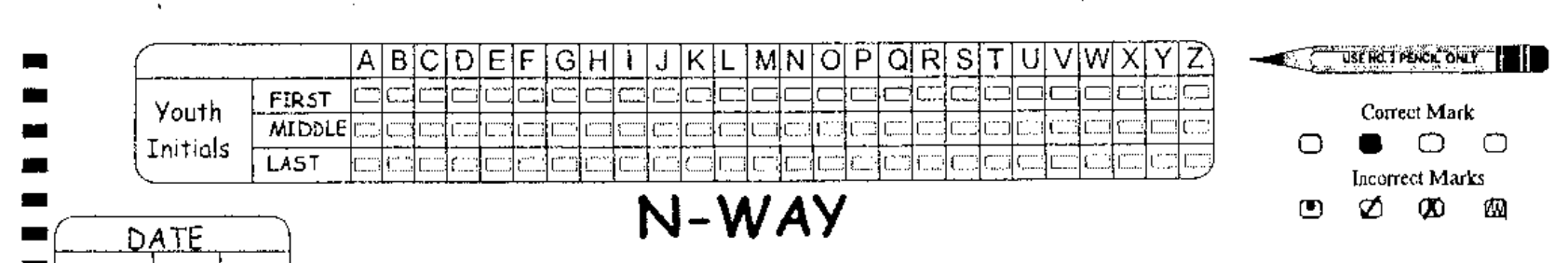

\section{During the past $\underline{Z}$ days: [Choose only $\underline{1}$ answer for each question.]}

18. I had trouble getting along with school staff (e.g., teachers, principals, other adult staff)
$\checkmark$ Rarely
$\square$ Somewhat less than usual
a About the same as usual
$\square$ Somewhat more than usual
c) Much more than usual

18a. How much did having trouble getting along with school staff disrupt my life?
$\square$ Not at alt
$\square$ A litte
$\square$ Somewhat
$\square$ A lot
$\square$ Extremely

18b. Generally, the intensity of trouble getting along with school staff was:

$\begin{array}{ccccccccc}\square & \square & \square & \square & \square & \square & \square & \square & \square \\ 1 & 2 & 3 & 4 & 5 & 6 & 7 & 8 & 9 \\ \text { EXTREMELY LOW } & & & \text { MODERATE } & & & \text { WORSTEVER }\end{array}$

18c. Generally, trouble getting along with school staff occurred:

$\square$ Early in Morning/Before School (6am-10am)

$\square$ Mid day (11am-1pm)

$\square$ Afternoon (2pm-3pm)

$\square$ Late Afternoon/After School (4pm-6pm)

$\square$ Early Evening/After Dinner (6pm-8pm)

$\checkmark$ Late Evening (9pm-1am)

$\square$ No particular time 


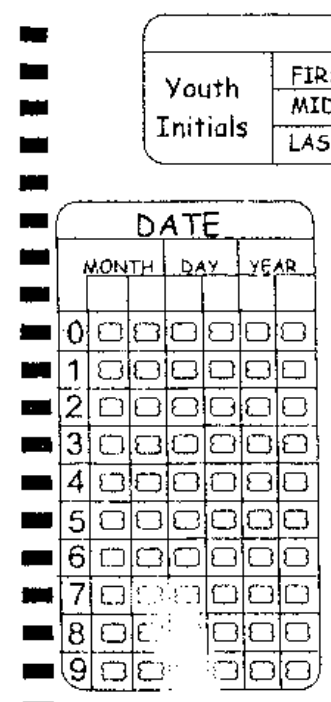

A. B C C D D ETF G G H I J K K L FIRST
MIDDLE

N-WAY

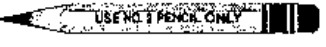

Correct Mark

$\square \bigcirc \square$

Incorrect Marks

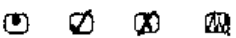

\section{During the past $\underline{Z}$ days: [Choose only $\underline{1}$ answer for each question.]}

19. I craved a cigarette

$\square$ Rarely

$\square$ Somewhat less than usual

$\square$ About the same as usual

$\square$ Somewhat more than usual

$\square$ Much more than usual

19a. How much did my cravings disrupt my life?
$\square$ Not at all
$\checkmark$ A little
$\square$ Somewhat
$\square$ A lot
$\square$ Extremely

19b. Generally, the intensity of my cravings was:

$$
\begin{array}{cccccccccc}
\square & \square & \square & \square & \square & \square & 9 & \square & \square & \square \\
1 & 2 & 3 & 4 & 5 & 6 & 7 & 8 & 9 & 10 \\
\text { VERY LOW } & & & \text { MODERATE } & & & \text { WORST EVER }
\end{array}
$$

19c. Generally, my strongest cravings occurred:
$\square$ Early in Morning/Before School (6am-10am)
$\square$ Mid day (11am-1pm)
$\square$ Afternoon (2pm-3pm)
$\square$ Late Afternoon/After School (4pm-6pm)
(3) Early Evening/After Dinner (6pm-8pm)
(.) Late Evening (9pm-1am)
E: No particular time 


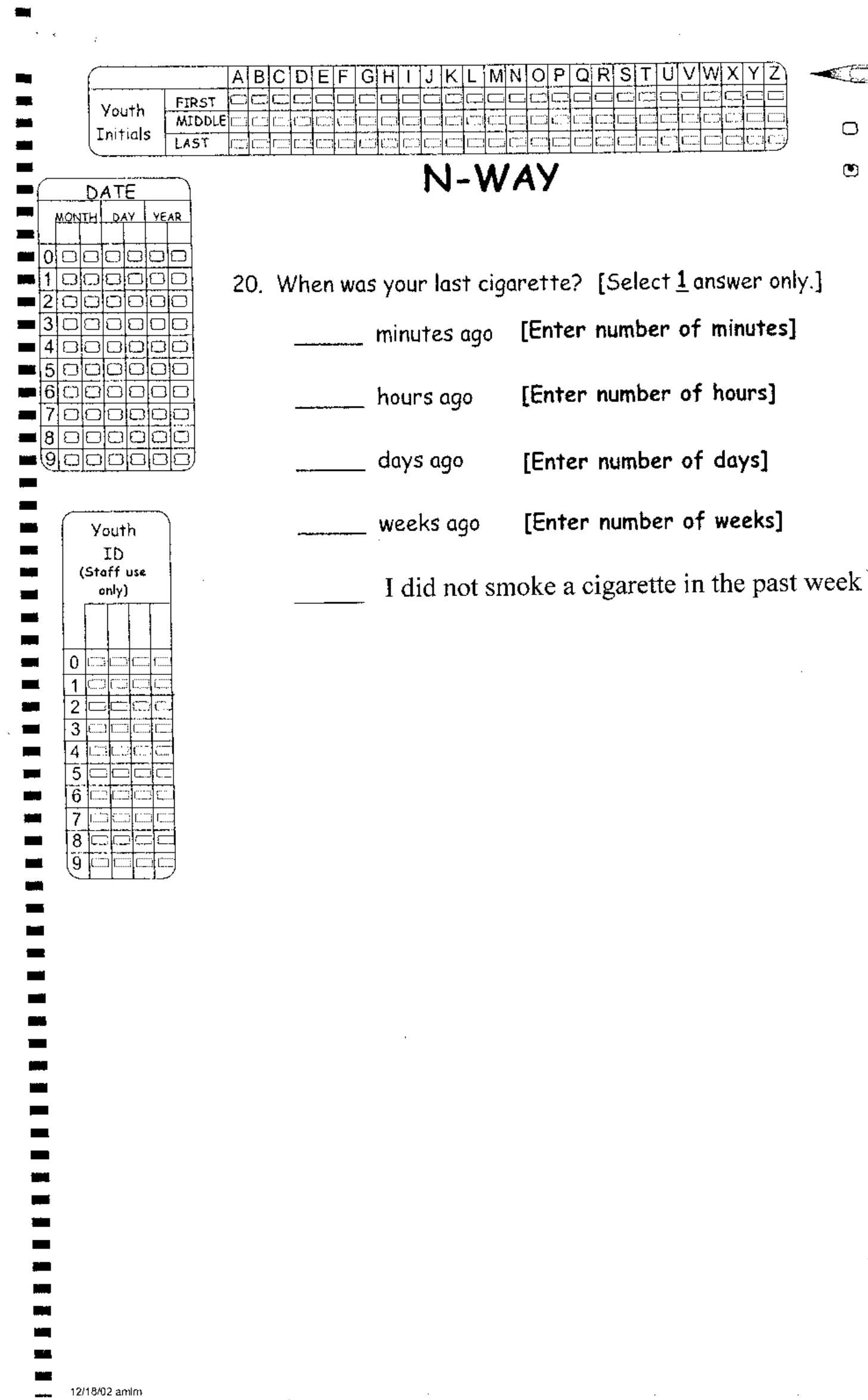
Incorrect Marks

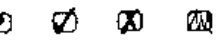

20. When was your last cigarette? [Select $\underline{1}$ answer only.] minutes ago [Enter number of minutes] hours ago [Enter number of hours] days ago [Enter number of days] weeks ago [Enter number of weeks] I did not smoke a cigarette in the past week. 


\section{Appendix D}

\section{N-WAY Supplement Form}

INSTRUCTIONS: Answer the question below by circling the response that best fits you: During the past $\underline{7}$ days: [Choose only $\underline{1}$ answer for each question.]

1. How often did you feel restless?
a. Not at all
b. A little
c. Sometimes
d. A lot
e. Almost always

2. How often did you feel angry?
a. Not at all
b. A little
c. Sometimes
d. A lot
e. Almost always

3. How often did you have headaches?
a. Not at all
b. A little
c. Sometimes
d. A lot
e. Almost always

4. How often did you have trouble concentrating?
a. Not at all
b. A little
c. Sometimes
d. A lot
e. Almost always

5. How often did you feel alert?
a. Not at all
b. A little
c. Sometimes
d. A lot
e. Almost always

6. How often did you feel tired?
a. Not at all
b. A little
c. Sometimes
d. A lot
e. Almost always 
7. How often did you feel stressed?
a. Not at all
b. A little
c. Sometimes
d. A lot
e. Almost always

8. How often did you feel hyper?
a. Not at all
b. A little
c. Sometimes
d. A lot
e. Almost always

9. How often did you feel depressed?
a. Not at all
b. A little
c. Sometimes
d. A lot
e. Almost always

10. How often did you feel nervous?
a. Not at all
b. A little
c. Sometimes
d. A lot
e. Almost always

11. How often did you feel dizzy?
a. Not at all
b. A little
c. Sometimes
d. A lot
e. Almost always

12. How often did you wake up during your sleep?
a. Not at all
b. A little
c. Sometimes
d. A lot
e. Almost always

13. How often did you feel irritable?
a. Not at all
b. A little
c. Sometimes
d. A lot
e. Almost always 
14. How often did you feel hungry?
a. Not at all
b. A little
c. Sometimes
d. A lot
e. Almost always

15. How often did you have trouble falling asleep?
a. Not at all
b. A little
c. Sometimes
d. A lot
e. Almost always

16. How often did you have trouble getting along with your family?
a. Not at all
b. A little
c. Sometimes
d. A lot
e. Almost always

17. How often did you have trouble getting along with your friends?
a. Not at all
b. A little
c. Sometimes
d. A lot
e. Almost always

18. How often did you have trouble getting along with your school staff (e.g., teachers, principals, other adult staff)?
a. Not at all
b. A little
c. Sometimes
d. A lot
e. Almost always

19. How often did you crave a cigarette?
a. Not at all
b. A little
c. Sometimes
d. A lot
e. Almost always 


\section{Appendix E}

\section{Modified Version of the Fagerström Tolerance Questionnaire (mFTQ)}

1. How many cigarettes a day do you smoke?
a. Over 26 cigarettes a day
b. About 16-25 cigarettes a day
c. About 1-15 cigarettes a day
d. Less than 1 a day

2. Do you inhale?
a. Always
b. Quite often
c. Seldom
d. Never

3. How soon after you wake up do you smoke your first cigarette?
a. Within the first 30 minutes
b. More than 30 minutes after waking but before noon
c. In the afternoon
d. In the evening

4. Which cigarette would you hate to give up?
a. First cigarette in the morning
b. Any other cigarette before noon
c. Any other cigarette afternoon
d. Any other cigarette in the evening

5. Do you find it difficult to refrain from smoking in places where it is forbidden (church, library, movies, etc.)?
a. Yes, very difficult
b. Yes, somewhat difficult
c. No, not usually difficult
d. No, not at all difficult

6. Do you smoke if you are so ill that you are in bed most of the day?
a. Yes, always
b. Yes, quite often
c. No, not usually
d. No, never

7. Do you smoke more during the first 2 hours than during the rest of the day?
a. Yes
b. No 